\title{
Estimation of different data compositions for early-season crop type classification
}

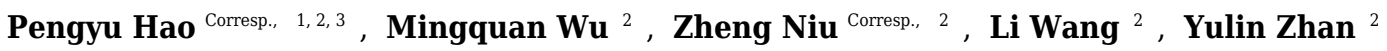 \\ ${ }^{1}$ Chinese Academy of Agricultural Sciences, Key Laboratory of Agricultural Remote Sensing, Ministry of Agriculture, China. (AGRIRS) / Institute of \\ Agricultural Resources and Regional Planning, Beiijng, China \\ 2 Chinese Academy of Sciences, The State Key Laboratory of Remote Sensing Science, Institute of Remote Sensing and Digital Earth, Beijing, China \\ 3 Shenzhen University, Key Laboratory for Geo-Environmental Monitoring of Coastal Zone of the National Administration of Surveying, Mapping and \\ Geolnformation \& Shenzhen Key Laboratory of Spatial Smart Sensing and Services, Shenzhen, China
}

Corresponding Authors: Pengyu Hao, Zheng Niu

Email address: haopy8296@163.com, niuzheng@radi.ac.cn

Timely and accurate crop type distribution maps are an important inputs for crop yield estimation and production forecasting as multi-temporal images can observe phenological differences among crops. Therefore, time series remote sensing data are essential for crop type mapping, and image composition has commonly been used to improve the quality of the image time series. However, the optimal composition period is unclear as long composition periods (such as compositions lasting half a year) are less informative and short composition periods lead to information redundancy and missing pixels.

In this study, we initially acquired daily 30m Normalized Difference Vegetation Index (NDVI) time series by fusing MODIS, Landsat, Gaofen and Huanjing (HJ) NDVI, and then composited the NDVI time series using four strategies (daily, 8-day, 16-day, and 32-day). We used Random Forest to identify crop types and evaluated the classification performances of the NDVI time series generated from four composition strategies in two studies regions from Xinjiang, China. Results indicated that crop classification performance improved as crop separabilities and classification accuracies increased, and classification uncertainties dropped in the green-up stage of the crops. When using daily NDVI time series, overall accuracies saturated at 113-day and 116-day in Bole and Luntai, and the saturated overall accuracies (OAs) were $86.13 \%$ and $91.89 \%$, respectively. Cotton could be identified $40 \sim 60$ days and 35 45 days earlier than the harvest in Bole and Luntai when using daily, 8-day and 16-day composition NDVI time series since both producer's accuracies (PAs) and user's accuracies (UAs) were higher than 85\%. Among the four compositions, the daily NDVI time series generated the highest classification accuracies. Although the 8-day, 16-day and 32-day compositions had similar saturated overall accuracies (around $85 \%$ in Bole and $83 \%$ in Luntai), the 8-day and 16-day compositions achieved these accuracies around 155-day in Bole and 133-day in Luntai, which were earlier than the 32-day composition (170-day in both Bole and Luntai). Therefore, when the daily NDVI time series cannot be acquired, the 16-day composition is recommended in this study. 


\section{Estimation of different data compositions for early-season crop type}

\section{2 classification}

3

4 Pengyu $\mathrm{Hao}^{1,2,3}$, Mingquan $\mathrm{Wu}^{2}$, Zheng $\mathrm{Niu}^{2 *}$, Li Wang ${ }^{2}$, Yulin Zhan ${ }^{2}$

6 1. Key Laboratory of Agricultural Remote Sensing, Ministry of Agriculture, China.

7 (AGRIRS)/Institute of Agricultural Resources and Regional Planning, Chinese Academy of

8 Agricultural Sciences, Beijing 100081, China;

9 2. The State Key Laboratory of Remote Sensing Science, Institute of Remote Sensing and

10 Digital Earth, Chinese Academy of Sciences, Beijing 100101, China;

11 3. Key Laboratory for Geo-Environmental Monitoring of Coastal Zone of the National

12 Administration of Surveying, Mapping and GeoInformation \& Shenzhen Key Laboratory of

13 Spatial Smart Sensing and Services, Shenzhen University, Shenzhen 518060, China.

14

$15 *$ Corresponding author: Zheng Niu

16 E-mail: niuzheng@radi.ac.cn 


\section{$17 \quad$ Abstract}

18 Timely and accurate crop type distribution maps are an important inputs for crop yield 19 estimation and production forecasting as multi-temporal images can observe phenological 20 differences among crops. Therefore, time series remote sensing data are essential for crop type 21 mapping, and image composition has commonly been used to improve the quality of the image time series. However, the optimal composition period is unclear as long composition periods (such as compositions lasting half a year) are less informative and short composition periods lead to information redundancy and missing pixels.

In this study, we initially acquired daily $30 \mathrm{~m}$ Normalized Difference Vegetation Index (NDVI) time series by fusing MODIS, Landsat, Gaofen and Huanjing (HJ) NDVI, and then composited the NDVI time series using four strategies (daily, 8-day, 16-day, and 32-day). We used Random Forest to identify crop types and evaluated the classification performances of the NDVI time series generated from four composition strategies in two studies regions from Xinjiang, China.

Results indicated that crop classification performance improved as crop separabilities and classification accuracies increased, and classification uncertainties dropped in the green-up stage of the crops. When using daily NDVI time series, overall accuracies saturated at 113-day and 116-day in Bole and Luntai, and the saturated overall accuracies (OAs) were 86.13\% and $91.89 \%$, respectively. Cotton could be identified 40 60 days and 35 45 days earlier than the harvest in Bole and Luntai when using daily, 8-day and 16-day composition NDVI time series since both producer's accuracies (PAs) and user's accuracies (UAs) were higher than $85 \%$. Among the four compositions, the daily NDVI time series generated the highest classification accuracies. Although the 8-day, 16-day and 32-day compositions had similar saturated overall accuracies (around $85 \%$ in Bole and $83 \%$ in Luntai), the 8-day and 16-day compositions achieved these accuracies around 155-day in Bole and 133-day in Luntai, which were earlier than the 32-day composition (170-day in both Bole and Luntai). Therefore, when the daily

42 NDVI time series cannot be acquired, the 16-day composition is recommended in this study.

\section{1. Introduction}

44 Multi-temporal remote sensing data, particularly vegetation indices (VI) time series, can 45 describe crop conditions during the crop growing season and have been widely used to classify 
46 crop types (Boryan et al. 2011; Waldhoff et al. 2017; Wardlow \& Egbert 2008). Most previous 47 studies have employed remote sensing images of the entire growing season to generate crop type 48 distribution maps (Howard \& Wylie 2014; Zhang et al. 2014), and the crop map is generally 49 acquired after the crop harvest. However, timeline is the first factor when considering a crop type 50 map because an early classification result might benefit decision-makers and the private sector 51 by helping growth monitor, forecasting crop yield and qualifying crop drought (Gallego J. et al. 52 2008; Skakun et al. 2017).

53 Considerable researches have been conducted on early-season crop type mapping (Azar et al. 54 55 2016; Vaudour et al. 2015; Villa et al. 2015), and there are two vital factors that contribute to early crop identification: the crop calendar and the remote sensing imagery characteristics. Previous early crop identification studies have shown that if crops are separable, high temporal frequency data such as Moderate Resolution Imaging Spectroradiometer (MODIS) can identify crops with a short image time series (Hao et al. 2015c; Zhou et al. 2013). The spatial resolution of high temporal density data, however, are relatively coarse (Verbeiren et al. 2008). Thus, mixed pixels may lead to serious misclassification in a heterogeneous landscape (Hao et al. 2015b). At finer spatial resolution, the possibility of obtaining imagery with dense temporal resolution is low. For example, Landsat ETM+ cannot provide cloud-free image in each season globally, especially during autumn and winter (Ju \& Roy 2008). Although Landsat and Huanjing (HJ) images have been used to improve the temporal resolution of image time series (Hao et al. 2014); in addition, Sentinel-2 satellite may provide optical images with higher spatial and temporal resolutions (10m and five-day) (ESA 2016), but the image time series still contain "missing values" due to cloud cover (Hao et al. 2015a).

Most classifiers cannot handle "missing values" within the image time series, but image time series at a good spatial resolution. such as $30 \mathrm{~m}$, are generally irregular because of low satellite revisit frequencies and cloud cover. One commonly used method used to reduce the "missing value" pixels is image composition (Xiong et al. 2017). However, the optimal composition period for cropland identification is not clear as short composition periods might describe dynamic land cover changes accurately, but missing pixels caused by cloud cover are also more likely to be included in the short composited image time series (van Leeuwen et al. 1999), and density time series generated from short compositions also lead to information redundancy (Low 
76 et al. 2013; Wardlow \& Egbert 2010). Therefore, the composition period should be a balance

77 between the number of missing pixels and the density of image time series.

78 To estimate the optimal composition period for crop type mapping at $30 \mathrm{~m}$ resolution, an

79 image time series with a high temporal density is firstly generated by fusing coarse and medium

80 spatial resolution data (Wu et al. 2015a). Gao et al. (2006) introduced the Spatial and Temporal 81 Adaptive Reflectance Fusion Model (STARFM) to blend MODIS and Landsat data. Some other 82 data fusion methods are based on the assumption that MODIS pixels are a linear combination of 83 each contributing land cover class (Maselli et al. 1998; Zhukov et al. 1999), but this is not the 84 real-case scenario (Wu et al. 2015a). Wu et al. (2012) assumed that pixels of the same land cover 85 have similar temporal variation characteristics and proposed a spatial and temporal data fusion 86 approach (STDFA). This method has the potential to synthesize daily imagery and products such 87 88 as land surface temperature (LST) and leaf area index (LAI) at a medium resolution (Wu et al. 2015b; Wu et al. 2015c).

The objectives of the study were to (1) generate NDVI time series of four different composition periods (daily, 8-day, 16-day and 32-day) from daily NDVI time series, and evaluate classification performances of the four image compositions and (2) test and analyze the potential of early-season crop identification using the NDVI time series of the four compositions.

\section{Study regions and data sets}

\section{2.1. Study regions}

Xinjiang is the most important cotton-growing region in China, contributing half of the national cotton yield (Wang et al. 2014; Xu et al. 2007). Early crop identification could help manage crop cultivation, particularly in terms of the cotton monitor. In this study, two representative study regions containing major crops in Xinjiang were selected.

The two study regions are located in Xinjiang Province, China (Figure 1). The first study region is Bole County $\left(44^{\circ} 20^{\prime}-45^{\circ} 23^{\prime} \mathrm{N}, 80^{\circ} 40^{\prime}-82^{\circ} 42^{\prime} \mathrm{E}\right)$, located in the northwest part of Xinjiang. The region has a temperate, continental climate characterized by dryness and drought. The annual average temperature and rainfall are $7.0^{\circ} \mathrm{C}$ and $202 \mathrm{~mm}$. Bole County is a representative region in north Xinjiang because this county contains the major crops such as cotton and grapes. The crop calendar of the crops in this study region is shown in Figure 2. Cotton and maize are sown in the middle of April and develop between May and August. Cotton 
106 is harvested in the middle of August and spring maize is harvested in September. Grapes

107 blossom in April and develop between April and June. Multiple grapes varieties lead to long

108 harvest period of grapes harvest (Figure 2). Watermelon is sown in early May, develops between

109 May and August and is then harvested in late August.

110 The second study region is Luntai County $\left(41^{\circ} 39^{\prime}-41^{\circ} 56^{\prime} \mathrm{N}, 84^{\circ} 00^{\prime}-84^{\circ} 21^{\prime} \mathrm{E}\right)$, located at

111 the Bayinguoleng Mongolian Autonomous Prefecture between Southern Tianshan and the north

112 of the Tarim Basin. It has a warm, temperate, continental, arid climate, and the annual average

113 temperature and rainfall are $10.9^{\circ} \mathrm{C}$ and $52 \mathrm{~mm}$. The main crops of Luntai are cotton, maize,

114 melons and winter wheat, and the crop calendar of these crops is shown in Figure 2. Winter

115 wheat is sown in early October, develops between October and the following May and matures

116 in early June. After the winter wheat is harvested, summer maize is sown, which develop over

117 July and August, and is harvest in September. Therefore, these fields have a winter wheat-

118 summer maize rotation, and we defined them as "wheat-maize" in this study. Cotton, spring

119 maize and melons are sown in April, melon develops between April and July and is harvest in

120 early August, cotton develops between May and August and is harvested in September and

121 October, spring maize develops between May and the middle of August and is harvested in late

122 August and early September. We define spring maize as "maize" in this study. As well as the

123 crops, there are also some orchards with apple and pear trees in Luntai. These trees blossom in

124 April and the fruits become ripe in late August / September.

125 2.2. Density NDVI time series

126 The daily NDVI time series at the $30 \mathrm{~m}$ resolution were obtained by fusing cloud-free

127 MODIS, Landat, HuanJing (HJ) and GaoFen (GF) NDVI during Day 97 320 for Bole in 2011

128 and Day 93 315 Luntai in 2013 (Wu et al. 2015d). Landsat, HJ and GF data have medium

129 spatial resolution (Landsat, HJ 30m and GF-WFV 16m). All this data were surface reflectance

130 and the data from Bole was georeferenced with the UTM WGS 84, zone 44N. The data from

131 Luntai was georeferenced with the UTM WGS 84, zone 45N. The HJ and GF data were

132 registered to the TM images, achieving an RMSE of less than 0.3 pixels using a second order

133 polynomial transformation and bi-linear resampling, and the spatial resolution of the data were

134 resampled to $30 \mathrm{~m}$. As these three medium resolution sensor systems (Landsat, GF and HJ) have

135 differences in parameters, bandwidth, acquisition time and spectral response (Gao et al. 2006),

136 the Landsat and GF NDVI were calibrated to HJ NDVI because HJ acquired the most cloud-free 
137 observations among the three sensor systems. The MOD09GA land surface reflectance product 138 was employed in this study, and the NDVI was then calculated. Next, we used the STDFA to 139 fuse the MODIS NDVI and HJ, GF NDVI and generated the daily NDVI time series. The fusion 140 method and the validation of the fusion NDVI time series were introduced by Wu et al. (2015d) 141 in detail. For each date, if we were able to acquire data in one of the four sensor systems, the 142 NDVI at 30m was recorded and vice versa. In this study, we tried to estimate the potential of 143 early season crop type classification and estimate the performance of the four image time series 144 compositions based on the daily NDVI time series at the $30 \mathrm{~m}$ resolution generated from the 145 MODIS, Landsat, GF and HJ NDVI fusion.

146 One limitation is that NDVI profiles of some crops included some confusion, which had 147 negative effects on classification performance. Previous studies have shown that multi-spectral 148 bands can achieve higher classification accuracy compared with NDVI (Waldner et al. 2015). 149 However, we only used NDVI in this study because the daily time series were obtained by fusing 150 MODIS NDVI with medium-resolution NDVI data from multi-sensors. We did not fuse MODIS 151 data and 30m images for the multi-spectral bands because multi-spectral bands from multi152 sensors have large difference due to different specific band designations and spectral response 153 functions; while, NDVI from nultiple sensors have less difference comparing with multi-spectral 154 bands (Hao et al. 2015a; Hao et al. 2014; Wu et al. 2015a). We have evaluated the similarity 155 between Landsat images and HJ images, the correlation between Landsat NDVI and HJ NDVI 156 was more similar to a 1:1 line than multi-spectral bands (Hao et al. 2014). In addition, the 157 optimal features selection results showed that NDVI contributes the most to identifying crop 158 types. Therefore, we used NDVI time series in this study, although they were not perfect (Hao et 159 al. 2015c).

\section{2.3. Image composition strategies}

161 There are four image composition periods in this study: Daily, 8-day, 16-day and 32-day 162 compositions (Table 1). For each composition period, the composited NDVI was the maximum 163 NDVI of the time range. For example, the max NDVI between Day 97 and 104 were defined as 164 the 8-day composition NDVI during that time range; then, if the end of a compositing period is 165 not reached, for instance at Day 100, the 8-day composited NDVI was the maximum NDVI 166 among Day 97 100.

\section{2.4. Ground reference data}


Ground-reference data were obtained from fieldwork in August 2011 in Bole, and

169

170

171

172

173

174

175

176

177

178

179

180

181

182

183

184

185

186

187

188

189

190

191

192

193

194

195

September 2013 in Luntai. Several 300m*300m sampling plots were surveyed across the study areas, and the crop type information was collected. The field boundaries within the plots were recorded using GPS and digitized as polygons. Authorizations to access agricultural fields were given verbally by the National Bureau of Statistics of China (NBS) Survey Office in Xinjiang and the native farmers. Next, plot polygons were extended to field polygons based on very high resolution images (Google Earth). We overlaid the field boundaries on Landsat images and shrank the field boundaries to ensure that all Landsat pixels enclosed in the polygons were pure crop pixels. Finally, the polygons were converted to pixel format using the TM grid (Figure 3). Several surveyed fields (polygons) were randomly selected for training and the others were used as validation. For both training and validation polygons, a portion of samples were selected randomly from the polygons and were used as training and validation samples. The number of surveyed fields and samples is shown in Table 2.

\section{Methods}

\subsection{Overview of the method}

A flowchart of this study is presented in Figure 4. First, we composited the NDVI time series using four composition strategies (daily, 8-day, 16-day, and 32-day compositions). Then, both Jeffries-Matusita $(\mathrm{JM})$ distance and the extension of JM distance $\left(\mathrm{J}_{\mathrm{Bh}}\right)$ were used to calculate the crop separability. Random Forest (RF) algorithm was used to classify the crop types and classification accuracy and uncertainty were both used to evaluate classification performance. The input NDVI time series was increased from one day to the entire crop growing season for each composition strategy. Finally, the potential of early season crop type mapping were evaluated using the crop separability, classification accuracy and uncertainty,

\subsection{Separability measure}

We used JM distance to measure the separability of each pair-wise crop because previous research proved that JM distance have high potential to measure crop separability (Medjahed et al. 2016; Murakami et al. 2001). The JM distance between a pair of crops could be calculated by equation (1):

$$
\operatorname{JM}\left(c_{\mathrm{i}}, \mathrm{c}_{\mathrm{j}}\right)=\int_{\mathrm{x}}\left(\sqrt{\mathrm{p}\left(\mathrm{x} \mid \mathrm{c}_{\mathrm{i}}\right)}-\sqrt{\mathrm{p}\left(\mathrm{x} \mid \mathrm{c}_{\mathrm{j}}\right)}\right)^{2} \mathrm{dx}
$$


196 where $\mathrm{x}$ is a span of VI time series values, and $c_{i}$ and $c_{j}$ are the two crop types under

197 consideration. Then, equation (1) could be simplified as JM $=2\left(1-\mathrm{e}^{-\mathrm{B}}\right)$, where

$$
B=\frac{1}{8}\left(\mu_{i}-\mu_{j}\right)^{T}\left(\frac{C_{i}+C_{j}}{2}\right)-1\left(\mu_{i}-\mu_{j}\right)+\frac{1}{2} \ln \left(\mid \frac{\left|C_{i}+C_{j}\right|}{2 \sqrt{\left|C_{i}\right| \times\left|C_{j}\right|} \mid}\right)
$$

$198 C_{i}$ and $C_{j}$ are the covariance matrices of classes $i$ and $j$, and $\left|C_{i}\right|$ and $\left|C_{j}\right|$ are the determinants of $C_{i}$

199 and $\mathrm{C}_{\mathrm{j}}$. The JM distance ranges from 0 to 2, and larger JM distance indicats higher level of 200 separability between the two classes (Adam \& Mutanga 2009).

201 When measuring the separability of multiple classes, different classes were given different 202 weights to account for the sample sizes. An extension of the JM distance $\left(\mathrm{J}_{\mathrm{Bh}}\right)$ was used for this 203 purpose (Bruzzone et al. 1995). $\mathrm{J}_{\mathrm{Bh}}$ was calculated using equation (6) based on Bhattacharyya 204 bounds:

$$
\mathrm{J}_{\mathrm{Bh}}=\sum_{\mathrm{i}=1 \mathrm{j}>i}^{\mathrm{N}} \sqrt{\mathrm{p}\left(\mathrm{w}_{\mathrm{i}}\right) \times \mathrm{p}\left(\mathrm{w}_{\mathrm{j}}\right)} \times \mathrm{JM}^{2}(\mathrm{i}, \mathrm{j})
$$

205 where $\mathrm{N}$ was the number of classes and $\mathrm{p}\left(\mathrm{w}_{\mathrm{i}}\right)$ and $\mathrm{p}\left(\mathrm{w}_{\mathrm{j}}\right)$ were the $\alpha$ priori probabilities of classes $\mathrm{i}$ and $\mathrm{j}$, respectively, which were calculated using the combination of training samples in Table 1.

\section{3.3. Classifier}

208 The Random Forest (RF) classifier was employed in this study. The RF model combines multiple classification trees, and the model output is determined by the majority vote of the

210 single classification trees (Breiman 2001). When training the RF model, each tree is constructed

211 using two-thirds of the training records, and the remaining one-third of the records are used for a

212 test classification, with an error referred to the "out-of-bag error" (OOB error). The RF could

213 handle high dimensional data effectively and have been widely employed for land cover 214 classification (Immitzer et al. 2016; Rodriguez-Galiano et al. 2012). Two free parameters of RF; 215 the number of trees (ntree) and the number of features to split the nodes (mtry), were defined as 2161000 and the square root of the total number of input features (Loosvelt et al. 2012), and both the 217 crop-label and probabilistic output were obtained using the Random Forest library for R 218 (Breiman et al. 2013).

\section{3.4. Accuracy assessment}


Classification accuracy and uncertainty were both used to evaluate classification 221 performance. The confusion-matrix-derived accuracy metrics, overall accuracy (OA), producer's 222 accuracy (PA), user's accuracy (UA) and Kappa coefficient, were used in this study (Congalton 223 1991). RF also provides the probabilistic output for each pixel, $\left(p_{1}(x), \cdots, p_{k}(x), \cdots, p_{K}(x), k=1,2, \cdots, K\right)$, 224 which could be used to generate classification uncertainties, and we calculated the $\alpha$ quadratic 225 entropy as classification uncertainty (Pal \& Bezdek 1994), (equation 4):

$$
\mathrm{H}(\mathrm{p}(\mathrm{x}))=\frac{1}{\mathrm{n} \times 2^{-2 \alpha}} \sum_{\mathrm{k}=1}^{\mathrm{K}} \mathrm{p}_{\mathrm{k}}^{\alpha}(\mathrm{x})\left(1-\mathrm{p}_{\mathrm{k}}(\mathrm{x})\right)^{\alpha}
$$

226 where $H(p(x))$ is the $\alpha$ quadratic entropy of the vector $p(x), p_{1}(x), \cdots, p_{K}(x)$ are the probabilistic

227

228

229

230 outputs, $\alpha$ is a user-defined value which ranges from 0 and 1 , and $\alpha=0.5$ is used in this study. And smaller $\mathrm{H}(\mathrm{p}(\mathrm{x}))$ means more reliable classification. One advantage of the $\alpha$ quadratic entropy is that it applies all information to the probability vector. Next, we calculated the ratio of the correctly classified pixels and wrongly classified pixels as the uncertainty ratio (equation 5):

$$
\text { Uncertainty Ratio }=\frac{\text { Average }\left(\text { Uncer }_{C}\right)}{\text { Average }\left(\text { Uncer }_{U}\right)}
$$

231 where Average $\left(\right.$ Uncer $\left._{C}\right)$ is the average uncertainty of all correctly identified pixels (validation 232 samples), and Average $\left(\right.$ Uncer $\left._{U}\right)$ is the average uncertainty of all misclassified pixels. Therefore, a 233 lower uncertainty ratio corresponds with a better classification performance.

\section{4. Results and discussions}

\section{4.1. Crop separability}

Figure 5 showed the effect of time series length on crop separability for each composition strategy. For all four compositions in both study regions, $\mathrm{J}_{\mathrm{Bh}}$ distance increased with time series length and reached saturation points; after the saturation points, longer time series did not improve crop separability significantly. In Bole, the daily composition NDVI time series reached the saturated point the earliest (the time series length was 107-day) and the saturated $\mathrm{J}_{\mathrm{Bh}}$ was

2415.53 ; the $\mathrm{J}_{\mathrm{Bh}}$ distance of the 8-day and 16-day composition NDVI time series saturated at 155242 day and 158-day, and the saturated $\mathrm{J}_{\mathrm{Bh}}$ distances were 5.63 and 5.22, respectively. $\mathrm{J}_{\mathrm{Bh}}$ distance of 243 the 32-day composition time series saturated the latest (193-day time series) and the saturated $\mathrm{J}_{\mathrm{Bh}}$ 244 was 4.47. In Luntai, the $\mathrm{J}_{\mathrm{Bh}}$ distances of the daily, 8-day and 16-day composition time series 245 reached saturated points at 170-day, and the saturated $\mathrm{J}_{\mathrm{Bh}}$ distances were 7.42, 7.21 and 7.02, 
246 respectively. The $\mathrm{J}_{\mathrm{Bh}}$ distance of the 32-day composition time series saturated the latest (196247 day), and the saturated $\mathrm{J}_{\mathrm{Bh}}$ distance was 6.67 .

248 Figure 6 and Figure 7 showed the effect of the time series length and image composition 249 strategies on pair-wise crop JM distances. Generally, crop separability increased with the time 250 series length and reached saturated points, and the daily time series reached saturated points the 251 earliest and had the highest JM distance. In Bole, cotton was confused with maize and grapes.

252 For cotton and grapes, the JM distance of the daily composition time series saturated at 88-day 253 and the saturated JM distance was 1.95. The 8-day composition and 16-day composition had 254 similar trends; the JM distance saturated at 134-day and 145-day, and the saturated JM distances 255 were 1.88 and 1.80 , respectively. For the 32-day composition time series, although the JM 256 distance saturated early (at 78-day), the saturated JM distance was 1.44, which indicated that the 257 32-day composition time series cannot distinguish between these two crops. For cotton and 258 maize, the JM distances of the daily, 8-day and 16-day composition time series saturated at 140259 day, 153-day and 161-day. The saturated JM distances were 1.94, 1.92 and 1.80. However, the 260 saturated JM distance of the 32-day composition time series was 1.36 at 161-day. In Luntai, 261 wheat-maize was highly separable from the other crops in the early season (30-day). Melon 262 crops were separable from cotton and maize at 90-day, but cotton and maize were still confusion. 263 The JM distances of the daily, 8-day and 16-day composition time series saturated at 143-day, 264 170-day and 172-day. The saturated JM distances were 1.91, 1.78 and 1.77. 32-day composition 265 had a low separability between these two crops as the saturated JM distance was 1.57 at 186-day.

\section{4.2. Classification accuracy}

267 Figure 8 showed the effect of time series length on overall classification accuracy (OA) and 268 Kappa coefficient for each composition strategy. Generally, the daily composition time series 269 had the best OA, the 8-day and 16-day composition time series had similar performances and the 270 32-day composition had the lowest accuracy. In Bole, both OA and Kappa coefficient increased 271 gradually with time series length and then saturated. The OA of the daily composition time series 272 saturated at 113-day, and the saturated OA and Kappa coefficient were 86.13\% and 0.7505 . The 273 OA of the 8-day and 16-day composition time series saturated at 153-day and 156-day, and their 274 saturated OAs were $85.31 \%$ and $85.10 \%$. However, the OA of the 32-day composition time 275 series saturated at 172-day, and the saturated OA was $85.22 \%$. In Luntai, the OA and Kappa 276 coefficient increased at 90-day, which was consistent with the separability result that the $J_{\mathrm{Bh}}$ 
277 distance increased at 90-day in Luntai. The OA of the daily, 8-day, 16-day and 32-day 278 composition time series saturated at 116-day, 133-day, 132-day and 170-day. The saturated OAs 279 were $91.89 \%, 83.81 \%, 83.95 \%$ and $82.41 \%$.

280 Figures 9 and 10 showed the effect of time series length on the PAs and UAs of each 281 composition. In Bole, the cotton PAs and UAs of the four image composition strategies had 282 similar trends and saturated at 90-day. The saturated PAs and UAs were about 95\% and 87\%. 283 The grape PAs and UAs of the daily, 8-day and 16-day image compositions showed similar 284 trends. The PAs saturated at 90-day and the UAs saturated at 120-day. The saturated PAs and 285 UAs were around $95 \%$ and $85 \%$, and the PA and UA of the 32-day composition saturated late. 286 The PA saturated at 130-day and the UA saturated at 150-day. For maize and watermelon, the 287 daily composition time series had the highest PA and UA, and the 32-day composition data had 288 the lowest accuracies. The 16-day and 32-day compositions performed similarly. The PA of 289 maize was low as the saturated PA of maize was around 87\%. In Luntai, the PAs and UAs of 290 melon, orchards and wheat-maize increased at 90-day, and all four composition strategies had 291 high accuracies (higher than 90\%). Meanwhile, cotton and maize were confused, and the 292 saturated PAs of maize were 65.3\%, 65.7\% and 64.6\% at 123-day, 155-day and 156-day for the 293 daily, 8-day and 16-day compositions. The maize PA of the 32-day time series was $47.2 \%$ when 294 the entire NDVI time series were used.

295 Maize and grape in Bole and maize in Luntai had relatively low accuracies for all four 296 composition strategies because of the confusion among the NDVI time series of these crops. The 297 confusion between cotton and grape in Bole was mainly caused by the large standard deviation 298 of grape NDVI profiles (Figure 11), which was consistent with the large variability of grape 299 reference NDVI time series (Hao et al. 2016). In addition, the confusion between cotton and 300 maize in both study regions was caused by the high similarity between the cotton and maize 301 NDVI time series (Figure 11).

302 We then evaluated how early early we can identify crops (when both the PA and UA are 303 higher than $85 \%$, Table 3) using time series with different composition strategies. In Bole, as the 304 cotton was harvested in late August (Figure 2), it could be identified 60 days before the harvest 305 using the daily NDVI time series and 40 days before the harvest using the 8-day and 16-day 306 composition time series. In Luntai, cotton was harvested in early September as the PAs and UAs

307 of the daily, 8-day and 16-day NDVI time series were higher than 85\% at 104-day, 113-day and 
308 115-day, and the cotton could be mapped 35 45 days before harvest. Meanwhile, as the cotton

309 PA and UA of the 32-day composition reached 85\% at 162-day and 170-day in Bole and Luntai,

310 the 32-day composition cannot support early-season cotton identification. Accuracies of 311 watermelon reached 85\% at 89-day, 123-day, 131-day and 131-day when using the daily, 8-day,

312 16-day and 32-day time series. As watermelon was harvested in late August in Bole, the daily

313 composition data was able to identify watermelon 40 days before the harvest. However, as grape

314 was harvested between late June and September in Bole and melon was harvested in early

315 August in Luntai (Figure 2), the early harvesting of grape in Bole and melon in Luntai cannot be

316 correctly identified by the four compositions in the early season.

317 Fundamentally, dense NDVI time series can describe crop growth conditions more precisely

318 (Zhan et al. 2017). For example, Zhang et al. (2009) found that vegetation phenology parameters

319 could be estimated higher accuracies using denser time series. As most summer crops have

320 different green-up speeds, dense time series have a higher probability of identifying such tiny

321 differences. While long composition periods (such as the 32-day composition) lead to late

322 classification saturation and low classification accuracy.

323 Although the daily NDVI time series achieved the best classification accuracy and the best

324 temporal efficiency, the $30 \mathrm{~m}$ image time series cannot be obtained at daily frequency in the most

325 cases. Thus, data composition should be considered in order to make full use of partly high-

326 quality data such as the Landsat-7 SCL-off data and partly cloud-free data (Google 2015; NASA

327 2015). Among the 8-day, 16-day and 32-day compositions, the 8-day and 16-day composition

328 data have earlier saturation data and a higher accuracy than the 32-day composition; thus, the 16-

329 day composition strategy is recommended in this study for the identification of crop types if the

330 daily NDVI time series cannot be acquired.

331 4.3. Classification uncertainty

332 Figure 12 showed the classification uncertainty of the two study regions. In both study 333 regions, the uncertainty ratio decreased with time series length. In Bole, the daily composition 334 time series had the lowest uncertainty ratio when the time series length was shorter than 140 days. 335 After day 140, the daily, 8-day and 16-day composition strategies had similar classification 336 uncertainties and the saturated uncertainty was around 0.4 at 140-day. The 32-day composition 337 had high classification uncertainty and the uncertainty ratio decreased to 0.4 at 170 -day. In 338 Luntai, the daily, 8-day and 16-day time series had similar uncertainties and the uncertainty ratio 
339 dropped at 90-day and finally decreased to 0.3. The classification uncertainty of the 32-day

340 composition time series was higher than the other compositions over the entire growing season.

\section{4.4. Crop Distributions}

342 Figures 13 and 14 showed that the crop distribution maps generated from the four NDVI

343 time series composition strategies were similar. Cotton was the dominant crop in both study

344 regions. In Bole, the crop fields were characterized by homogenous crop fields with large field

345 sizes. Compared with crop the distribution maps generated from the daily, 8-day and 16-day

346 composition time series, the crop map derived from the 32-day composition time series result

347 was more speckled, in particular some cotton pixels at the field boundaries were mislabeled as

348 grape crops. The cropland in Luntai was fragmented, so there were a large number of mixed

349 pixels in the $30 \mathrm{~m}$ image time series. These mixed pixels had low NDVI because they comprised

350 crops and the farm lanes. As melon had lower NDVI than cotton, maize and orchards, the mixed

351 pixels were mostly misclassified as melon. As our validation samples were all pure pixels, the

352 accuracy assessments did not describe the misclassifications of the mixed pixels in Luntai.

\section{5. Conclusion}

354 This study compared the performances of daily, 8-day, 16-day and 32-day composition NDVI time series for crop types classification and reached the following conclusions: (1) the crops could be classified early as crop separability, classification accuracies and uncertainties saturated early. When using the daily composition NDVI time series, the OAs saturated at 113day and 116-day, and the saturated OAs were $86.13 \%$ and $91.89 \%$ in Bole and Luntai. Longer time series could not improve the classification accuracy. (2) Cotton could be identified 40 60 days and 35 45 days before harvesting in Bole and Luntai when using the daily, 8-day and 16day composition NDVI time series as both the PAs and UAs were higher than $85 \%$. (3) The daily NDVI time series outperformed the other composition strategies because of the higher composition strategy was recommended in this study as the 8-day and 16-day compositions generated similar classification accuracies and outperformed the 32-day composition results. In the future, as more sensors or even geosynchronous orbit satellites ( $\mathrm{Xu}$ et al. 2017) at a medium resolution become available, we would further improve the crop classification in early season.

\section{Acknowledgments:}



the native farmers for help us collect field data in Xinjiang.

\section{References}

372 Adam E, and Mutanga O. 2009. Spectral discrimination of papyrus vegetation (Cyperus papyrus L.) in swamp

373

374

375

376

377

378

379

380

381

382

383

384

385

386

387

388

389

390

391

392

393

394

395

396

397

398

399

400

401

402

403

404

405

406 wetlands using field spectrometry. Isprs Journal of Photogrammetry and Remote Sensing 64:612-620. http://dx.doi.org/10.1016/j.isprsjprs.2009.04.004

Azar R, Villa P, Stroppiana D, Crema A, Boschetti M, and Brivio PA. 2016. Assessing in-season crop classification performance using satellite data: a test case in Northern Italy. European Journal of Remote Sensing 49:361-380. 10.5721/EuJRS20164920

Boryan C, Yang ZW, Mueller R, and Craig M. 2011. Monitoring US agriculture: the US Department of Agriculture, National Agricultural Statistics Service, Cropland Data Layer Program. Geocarto International 26:341-358. 10.1080/10106049.2011.562309

Breiman L. 2001. Random forests. Machine Learning 45:5-32. 10.1023/a:1010933404324

Breiman L, Cutler A, Liaw A, and Wiener M. 2013. Breiman and Cutler's random forests for classification and regression.

Bruzzone L, Roli F, and Serpico SB. 1995. An extension of the Jeffreys-Matusita distance to multiclass cases for feature selection. leee Transactions on Geoscience and Remote Sensing 33:1318-1321. $10.1109 / 36.477187$

Congalton RG. 1991. A review of assessing the accuracy of classifications of remotely sensed data. Remote Sensing of Environment 37:35-46. http://dx.doi.org/10.1016/0034-4257(91)90048-B

ESA. 2016. Sentinel-2 for Agriculture. Available at http://www.esa-sen2agri.org/SitePages/sentinel2.aspx.

Gallego J., Craig M., Michaelsen J., Bossyns B., and S. F. 2008. Best practices for crop area estimation with Remote Sensing.

Gao F, Masek J, Schwaller M, and Hall F. 2006. On the blending of the Landsat and MODIS surface reflectance: Predicting daily Landsat surface reflectance. leee Transactions on Geoscience and Remote Sensing 44:2207-2218. 10.1109/tgrs.2006.872081

Gong P, Wang J, Yu L, Zhao YC, Zhao YY, Liang L, Niu ZG, Huang XM, Fu HH, Liu S, Li CC, Li XY, Fu W, Liu CX, Xu Y, Wang XY, Cheng Q, Hu LY, Yao WB, Zhang H, Zhu P, Zhao ZY, Zhang HY, Zheng YM, Ji LY, Zhang YW, Chen H, Yan A, Guo JH, Yu L, Wang L, Liu XJ, Shi TT, Zhu MH, Chen YL, Yang GW, Tang P, Xu B, Giri C, Clinton N, Zhu ZL, Chen J, and Chen J. 2013. Finer resolution observation and monitoring of global land cover: first mapping results with Landsat TM and ETM+ data. International Journal of Remote Sensing 34:2607-2654. 10.1080/01431161.2012.748992

Google. 2015. Google Earth Engine. Available at https://developers.google.com/earth-engine/.

Hao P, Wang L, and Niu Z. 2015a. Comparison of Hybrid Classifiers for Crop Classification Using Normalized Difference Vegetation Index Time Series: A Case Study for Major Crops in North Xinjiang, China. PLoS ONE 10:e0137748. 10.1371/journal.pone.0137748

Hao P, Wang L, and Niu Z. 2015b. Potential of multitemporal Gaofen-1 panchromatic/multispectral images for crop classification: case study in Xinjiang Uygur Autonomous Region, China. Journal of Applied Remote Sensing 
9:096035-096035. 10.1117/1.JRS.9.096035

Hao P, Wang L, Zhan Y, and Niu Z. 2016. Using Moderate-Resolution Temporal NDVI Profiles for High-Resolution Crop Mapping in Years of Absent Ground Reference Data: A Case Study of Bole and Manas Counties in Xinjiang, China. Isprs International Journal of Geo-Information 5:67.

Hao PY, Zhan YL, Wang L, Niu Z, and Shakir M. 2015c. Feature Selection of Time Series MODIS Data for Early Crop Classification Using Random Forest: A Case Study in Kansas, USA. Remote Sensing 7:5347-5369. $10.3390 /$ rs70505347

Hao; P, Wang; L, Niu; Z, Aablikim; A, Huang; N, Xu; S, and Chen; F. 2014. The Potential of Time Series Merged from Landsat-5 TM and HJ-1 CCD for Crop Classification: A Case Study for Bole and Manas Counties in Xinjiang, China. Remote Sensing 6:7610-7631. 10.3390/rs6087610

Howard DM, and Wylie BK. 2014. Annual Crop Type Classification of the US Great Plains for 2000 to 2011. Photogrammetric Engineering and Remote Sensing 80:537-549.

Immitzer M, Vuolo F, and Atzberger C. 2016. First Experience with Sentinel-2 Data for Crop and Tree Species Classifications in Central Europe. Remote Sensing 8:166.

Ju JC, and Roy DP. 2008. The availability of cloud-free Landsat ETM plus data over the conterminous United States and globally. Remote Sensing of Environment 112:1196-1211. 10.1016/j.rse.2007.08.011

Loosvelt L, Peters J, Skriver H, Lievens H, Van Coillie FMB, De Baets B, and Verhoest NEC. 2012. Random Forests as a tool for estimating uncertainty at pixel-level in SAR image classification. International Journal of Applied Earth Observation and Geoinformation 19:173-184. 10.1016/j.jag.2012.05.011

Low F, Michel U, Dech S, and Conrad C. 2013. Impact of feature selection on the accuracy and spatial uncertainty of per-field crop classification using Support Vector Machines. Isprs Journal of Photogrammetry and Remote Sensing 85:102-119. 10.1016/j.isprsjprs.2013.08.007

Maselli F, Gilabert MA, and Conese C. 1998. Integration of high and low resolution NDVI data for monitoring vegetation in Mediterranean environments. Remote Sensing of Environment 63:208-218. 10.1016/s00344257(97)00131-4

Medjahed SA, Ait Saadi T, Benyettou A, and Ouali M. 2016. Gray Wolf Optimizer for hyperspectral band selection. Applied Soft Computing 40:178-186. 10.1016/j.asoc.2015.09.045

Murakami T, Ogawa S, Ishitsuka N, Kumagai K, and Saito G. 2001. Crop discrimination with multitemporal SPOT/HRV data in the Saga Plains, Japan. International Journal of Remote Sensing 22:1335-1348. 10.1080/01431160151144378

NASA. 2015. MODIS: Moderate Resolution Imaging Spectroradiometer. Available at http://nsidc.org/data/modis/ (accessed Dec, 31, 2015 2015).

Pal NR, and Bezdek JC. 1994. MEASURING FUZZY UNCERTAINTY. leee Transactions on Fuzzy Systems 2:107-118. 10.1109/91.277960

Rodriguez-Galiano VF, Chica-Olmo M, Abarca-Hernandez F, Atkinson PM, and Jeganathan C. 2012. Random Forest classification of Mediterranean land cover using multi-seasonal imagery and multi-seasonal texture. Remote Sensing of Environment 121:93-107. 10.1016/j.rse.2011.12.003

Skakun S, Franch B, Vermote E, Roger J-C, Becker-Reshef I, Justice C, and Kussul N. 2017. Early season large-area winter crop mapping using MODIS NDVI data, growing degree days information and a Gaussian mixture 
446

447

448

449

450

451

452

453

454

455

456

457

458

459

460

461

462

463

464

465

466

467

468

469

470

471

472

473

474

475

476

477

478

479

480

481

482

483

484

model. Remote Sensing of Environment 195:244-258. https://doi.org/10.1016/j.rse.2017.04.026

van Leeuwen WJD, Huete AR, and Laing TW. 1999. MODIS Vegetation Index Compositing Approach: A Prototype with AVHRR Data. Remote Sensing of Environment 69:264-280. https://doi.org/10.1016/S00344257(99)00022-X

Vaudour E, Noirot-Cosson PE, and Membrive O. 2015. Early-season mapping of crops and cultural operations using very high spatial resolution Pléiades images. International Journal of Applied Earth Observation and Geoinformation 42:128-141. 10.1016/j.jag.2015.06.003

Verbeiren S, Eerens H, Piccard I, Bauwens I, and Van Orshoven J. 2008. Sub-pixel classification of SPOTVEGETATION time series for the assessment of regional crop areas in Belgium. International Journal of Applied Earth Observation and Geoinformation 10:486-497. 10.1016/j.jag.2006.12.003

Villa P, Stroppiana D, Fontanelli G, Azar R, and Brivio P. 2015. In-Season Mapping of Crop Type with Optical and XBand SAR Data: A Classification Tree Approach Using Synoptic Seasonal Features. Remote Sensing 7:12859-12886. 10.3390/rs71012859

Waldhoff G, Lussem U, and Bareth G. 2017. Multi-Data Approach for remote sensing-based regional crop rotation mapping: A case study for the Rur catchment, Germany. International Journal of Applied Earth Observation and Geoinformation 61:55-69. https://doi.org/10.1016/j.jag.2017.04.009

Waldner F, Lambert M-J, Li W, Weiss M, Demarez V, Morin D, Marais-Sicre C, Hagolle O, Baret F, and Defourny P. 2015. Land Cover and Crop Type Classification along the Season Based on Biophysical Variables Retrieved from Multi-Sensor High-Resolution Time Series. Remote Sensing 7:10400-10424. 10.3390/rs70810400

Wang L, Wang C, Hao P, Shi K, Abdullah A, and leee. 2014. Cotton Area Estimation Using Muti-sensor RS Data and Big Plot Survey in Xinjiang. Third International Conference on Agro-Ggeoinformatics. p 246-250.

Wardlow BD, and Egbert SL. 2008. Large-area crop mapping using time-series MODIS $250 \mathrm{~m}$ NDVI data: An assessment for the U.S. Central Great Plains. Remote Sensing of Environment 112:1096-1116. http://dx.doi.org/10.1016/j.rse.2007.07.019

Wardlow BD, and Egbert SL. 2010. A comparison of MODIS 250-m EVI and NDVI data for crop mapping: a case study for southwest Kansas. International Journal of Remote Sensing 31:805-830. 10.1080/01431160902897858

Wu M, Huang W, Niu Z, and Wang C. 2015a. Generating Daily Synthetic Landsat Imagery by Combining Landsat and MODIS Data. Sensors 15:24002-24025. 10.3390/s150924002

Wu M, Li H, Huang W, Niu Z, and Wang C. 2015b. Generating daily high spatial land surface temperatures by combining ASTER and MODIS land surface temperature products for environmental process monitoring. Environmental Science-Processes \& Impacts 17:1396-1404. 10.1039/c5em00254k

Wu M, Wu C, Huang W, Niu Z, and Wang C. 2015c. High-resolution Leaf Area Index estimation from synthetic Landsat data generated by a spatial and temporal data fusion model. Computers and Electronics in Agriculture 115:1-11. 10.1016/j.compag.2015.05.003

Wu M, Zhang X, Huang W, Niu Z, Wang C, Li W, and Hao P. 2015d. Reconstruction of Daily $30 \mathrm{~m}$ Data from HJ CCD, GF-1 WFV, Landsat, and MODIS Data for Crop Monitoring. Remote Sensing 7:16293-16314. $10.3390 /$ rs71215826

Wu MQ, Niu Z, Wang CY, Wu CY, and Wang L. 2012. Use of MODIS and Landsat time series data to generate high- 
485

486

487

488

489

490

491

492

493

494

495

496

497

498

499

500

501

502

503

504

505

506 resolution temporal synthetic Landsat data using a spatial and temporal reflectance fusion model. Journal of Applied Remote Sensing 6. 10.1117/1.jrs.6.063507

Xiong J, Thenkabail P, Tilton J, Gumma M, Teluguntla P, Oliphant A, Congalton R, Yadav K, and Gorelick N. 2017. Nominal 30-m Cropland Extent Map of Continental Africa by Integrating Pixel-Based and Object-Based Algorithms Using Sentinel-2 and Landsat-8 Data on Google Earth Engine. Remote Sensing 9:1065.

Xu J, Liang Y, Liu J, and Huang Z. 2017. Multi-Frame Super-Resolution of Gaofen-4 Remote Sensing Images. Sensors $17: 2142$.

Xu W, Xinxiang NIU, and Xiuju B. 2007. The Calculations and Analyses on Thermal Production Potential of Cotton in Xinjiang. Cotton Science 19:455-460.

Zhan Y, Shakir M, Hao P, and Niu Z. 2017. The effect of EVI time series density on crop classification accuracy. Optik - International Journal for Light and Electron Optics 157.

Zhang JH, Feng LL, and Yao FM. 2014. Improved maize cultivated area estimation over a large scale combining MODIS-EVI time series data and crop phenological information. Isprs Journal of Photogrammetry and Remote Sensing 94:102-113. 10.1016/j.isprsjprs.2014.04.023

Zhang X, FriedI MA, and Schaaf CB. 2009. Sensitivity of vegetation phenology detection to the temporal resolution of satellite data. International Journal of Remote Sensing 30:2061-2074. 10.1080/01431160802549237

Zhou FQ, Zhang AN, and Townley-Smith L. 2013. A data mining approach for evaluation of optimal time-series of MODIS data for land cover mapping at a regional level. Isprs Journal of Photogrammetry and Remote Sensing 84:114-129. 10.1016/j.isprsjprs.2013.07.008

Zhukov B, Oertel D, Lanzl F, and Reinhackel G. 1999. Unmixing-based multisensor multiresolution image fusion. leee Transactions on Geoscience and Remote Sensing 37:1212-1226. 10.1109/36.763276 
Figure 1

The location of Study regions in Xinjiang

The location of Bole County and Luntai County in Xinjiang and; zoom into the study region (right part).

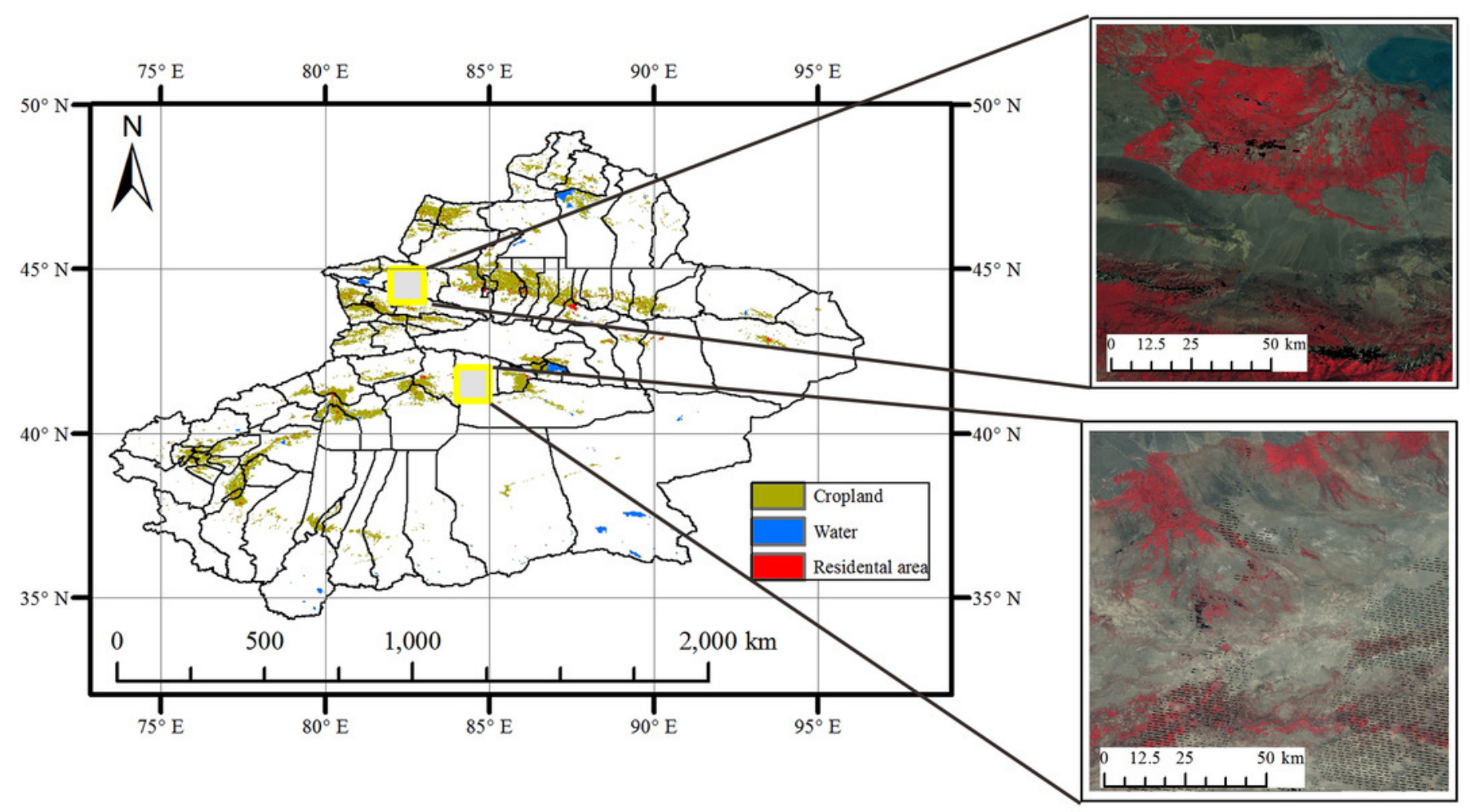


Figure 2

Crop calendar of the major crops in this study

(a) Bole

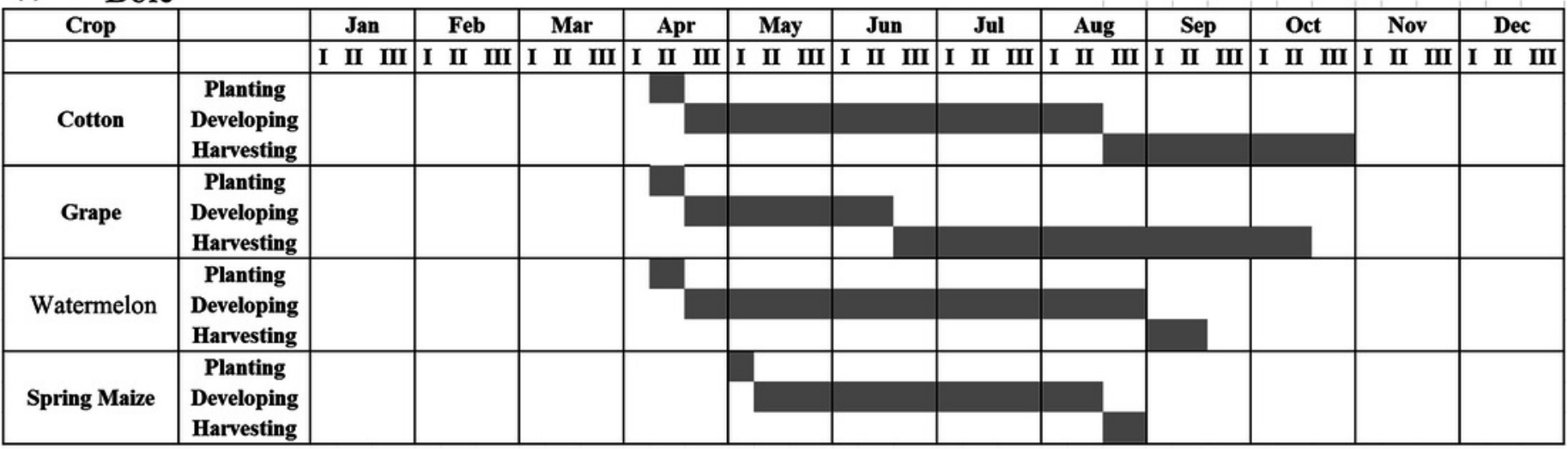

(b) Luntai

\begin{tabular}{|c|c|c|c|c|c|c|c|c|c|c|c|c|c|}
\hline Crop & & Jan & Feb & Mar & Apr & \begin{tabular}{|l|} 
May \\
\end{tabular} & Jun & \begin{tabular}{|l|} 
Jul \\
\end{tabular} & Aug & \begin{tabular}{|l} 
Sep \\
\end{tabular} & Oct & \begin{tabular}{|l} 
Nov \\
\end{tabular} & Dec \\
\hline & & I II III & I II III & I II III & I II III & I II III & I II III & I II III & I II III & I II III & I II III & I II III & I II III \\
\hline & Planting & & & & & & & & & & & & \\
\hline Winter Wheat & Developing & & & & & & & & & & & & \\
\hline & Harvesting & & & & & & & & & & & & \\
\hline & Planting & & & & & & & & & & & & \\
\hline Spring Maize & $\begin{array}{l}\text { Developing } \\
\text { Harvesting }\end{array}$ & & & & & & & & & & & & \\
\hline Summer Maize & $\begin{array}{c}\text { Planting } \\
\text { Developing } \\
\text { Harvesting }\end{array}$ & & & & & & & & & & & & \\
\hline Cotton & $\begin{array}{c}\text { Planting } \\
\text { Developing }\end{array}$ & & & & & & & & & & & & \\
\hline & Harvesting & & & & & & & & & & & & \\
\hline & Planting & & & & & & & & & & & & \\
\hline Melon & $\begin{array}{l}\text { Developing } \\
\text { Harvesting }\end{array}$ & & & & & & & & & & & & \\
\hline
\end{tabular}




\section{Figure 3}

Converting the field survey plots to polygons

(a) Three field surveyed plots; (b) the polygons extended from field plots and (c) the sample points (green points) on the Landsat image.
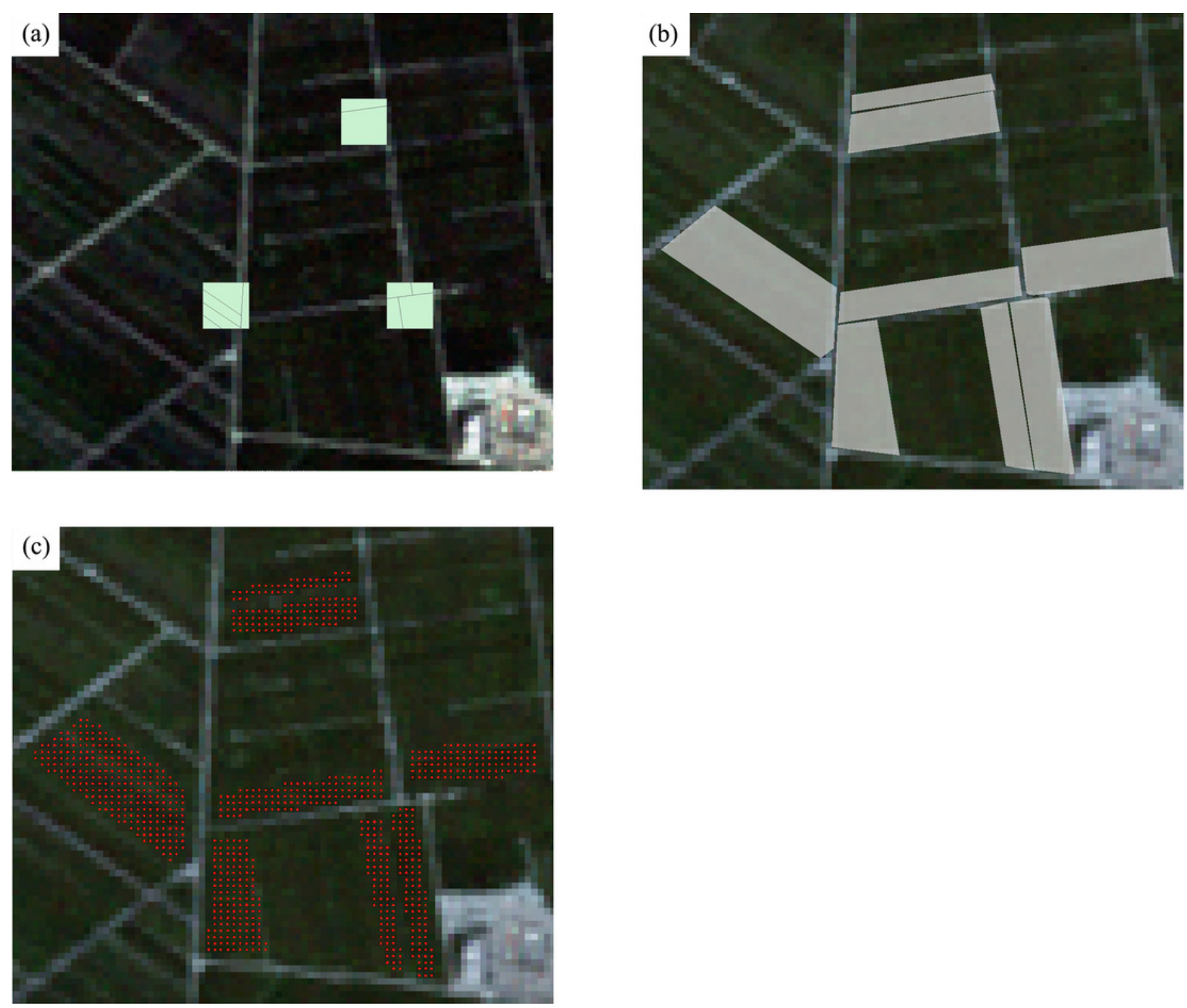


\section{Figure 4}

\section{Flowchart of this study}

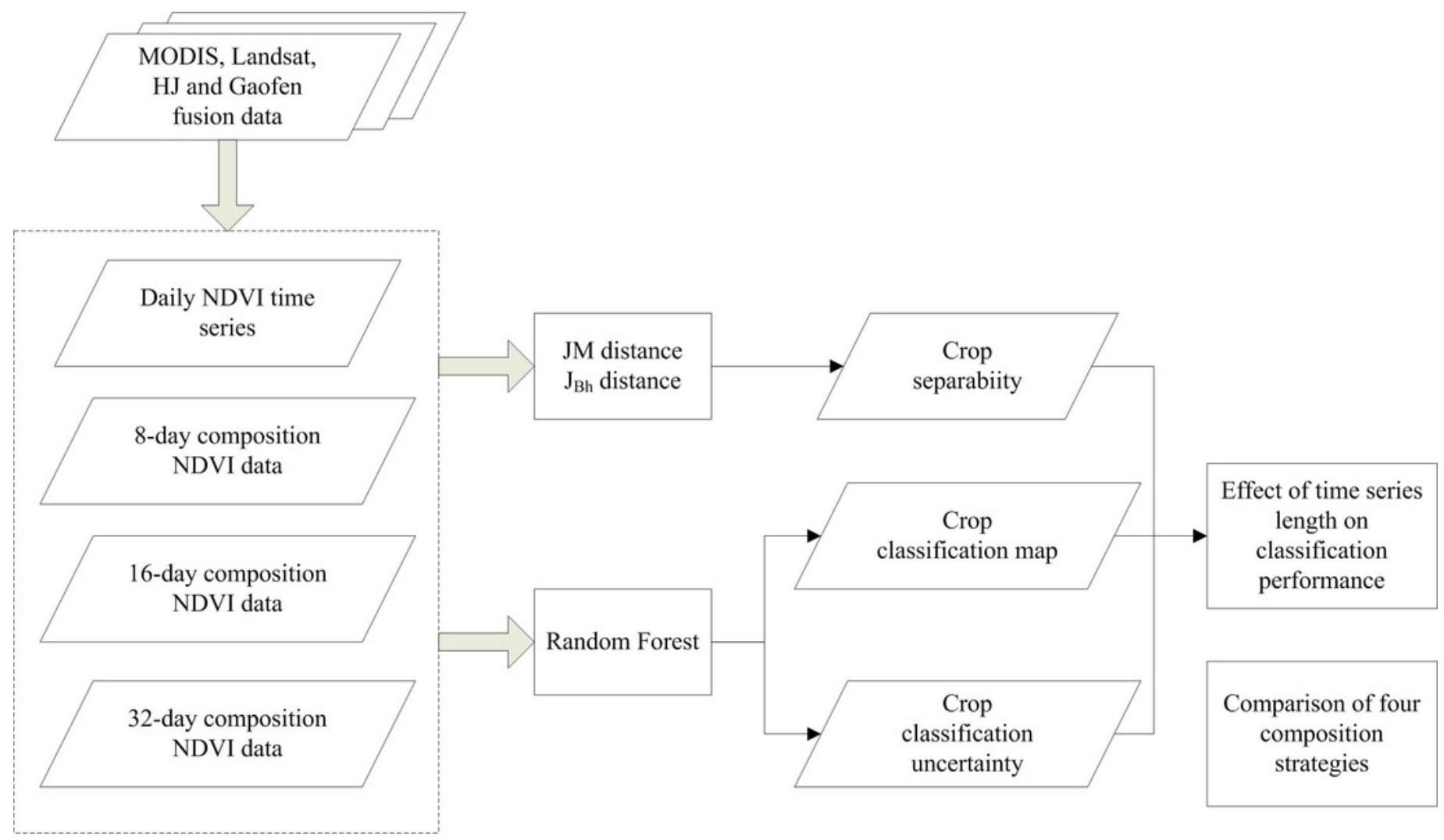


Figure 5

Crop separability of four image composition strategies in Bole and Luntai

(a)

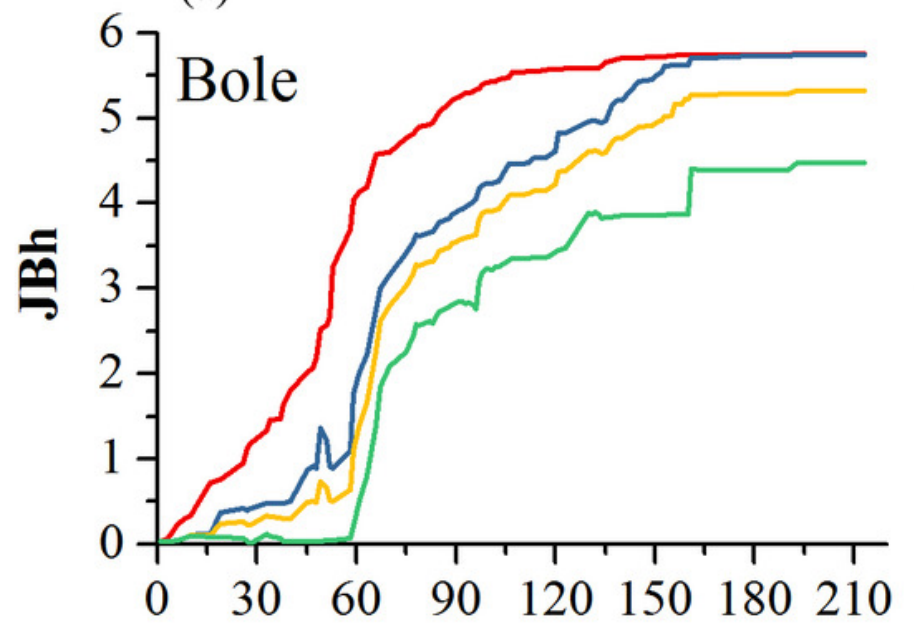

Time Series Length (b)

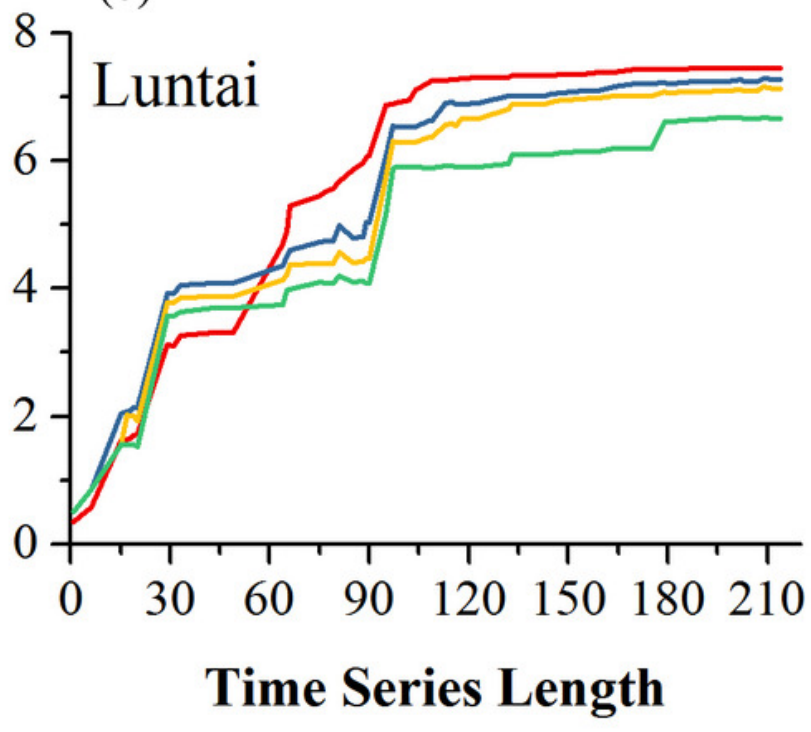

32 day 
Figure 6

Pair-wise JM distance for different composition strategies (Bole)
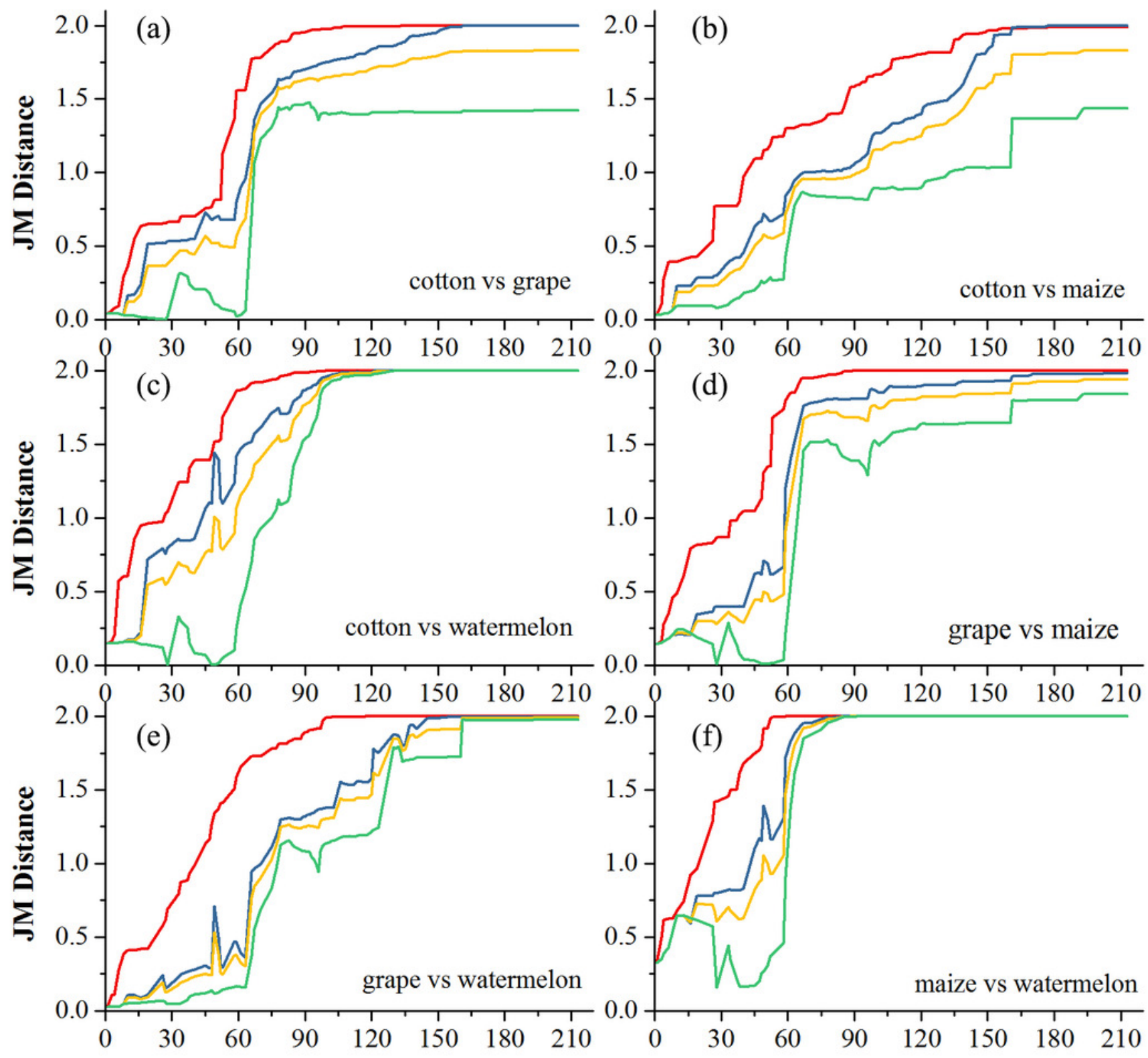

Time Series Length

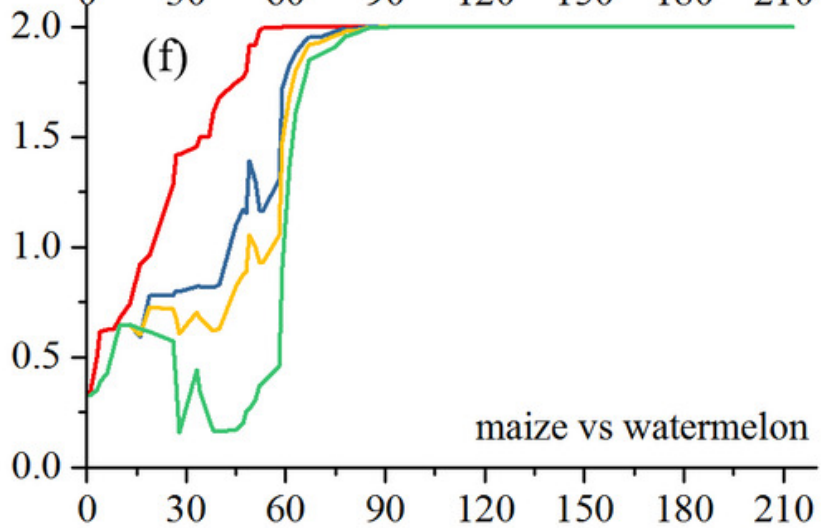

Time Series Length

- Daily -8 day -16 day -32 day


Figure 7

Pair-wise JM distance for different composition strategies (Luntai) 

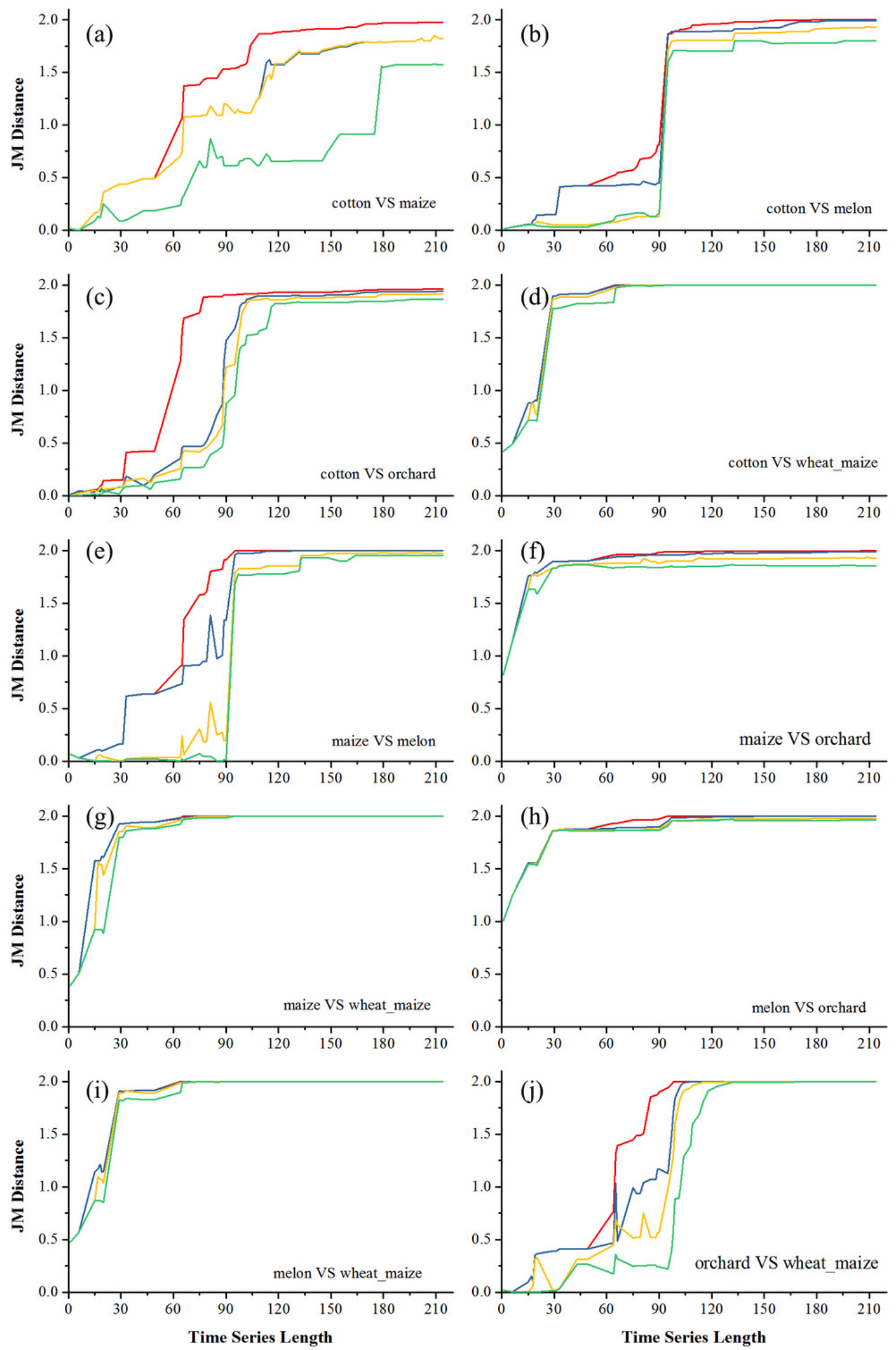
Figure 8

Overall accuracy and Kappa coefficient in Bole and Luntai
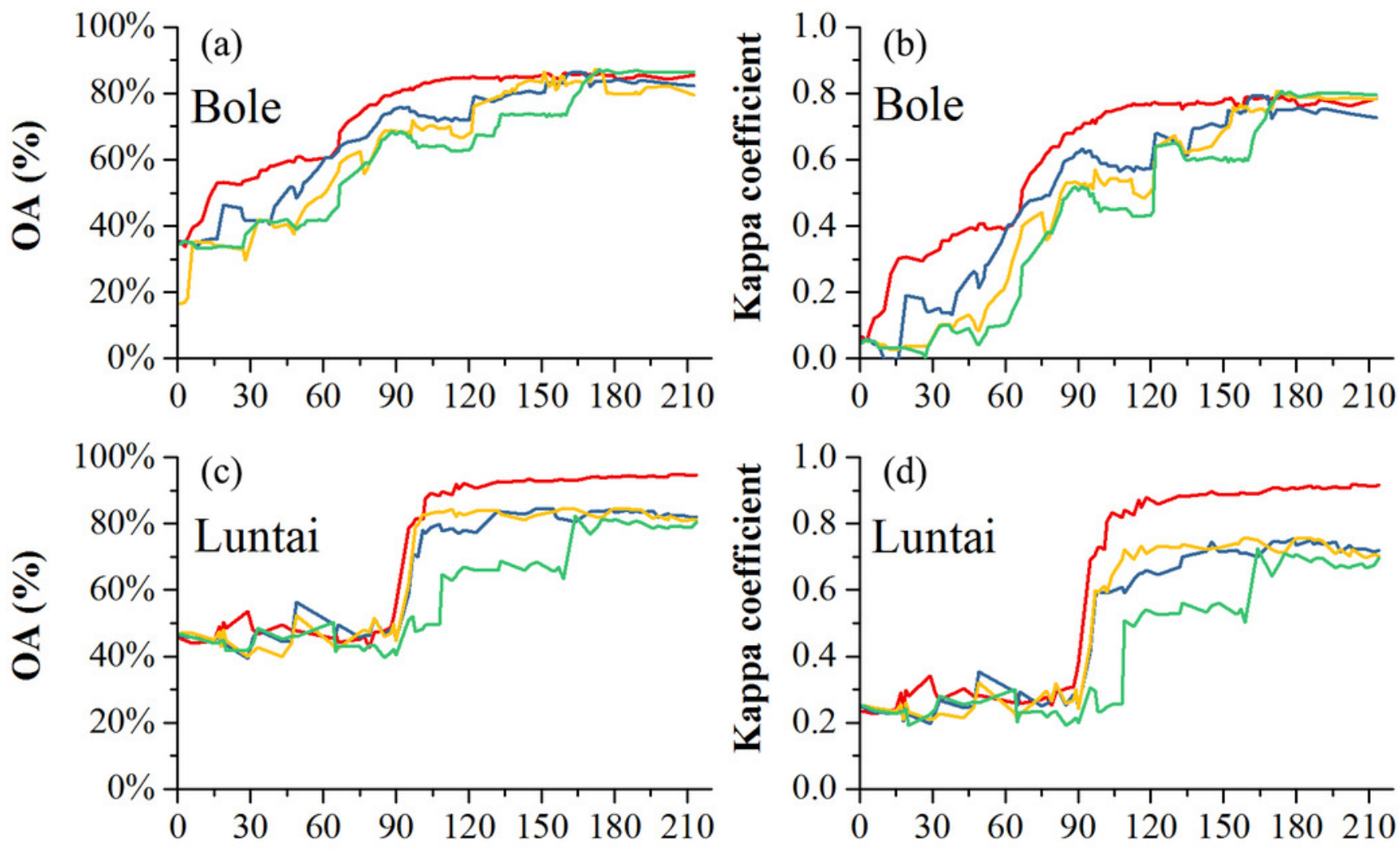

Time Series Length

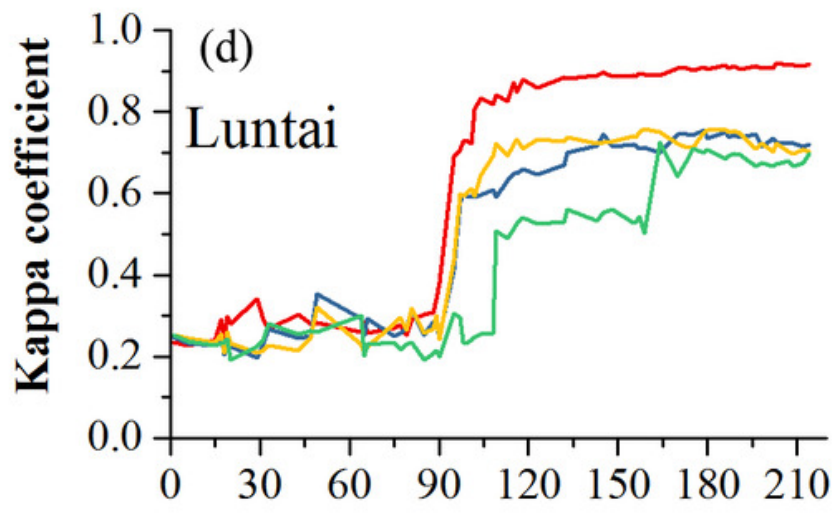

Time Series Length

- Daily -8 day -16 day -32 day


Figure 9

Producer's accuracies and user's accuracies in Bole 

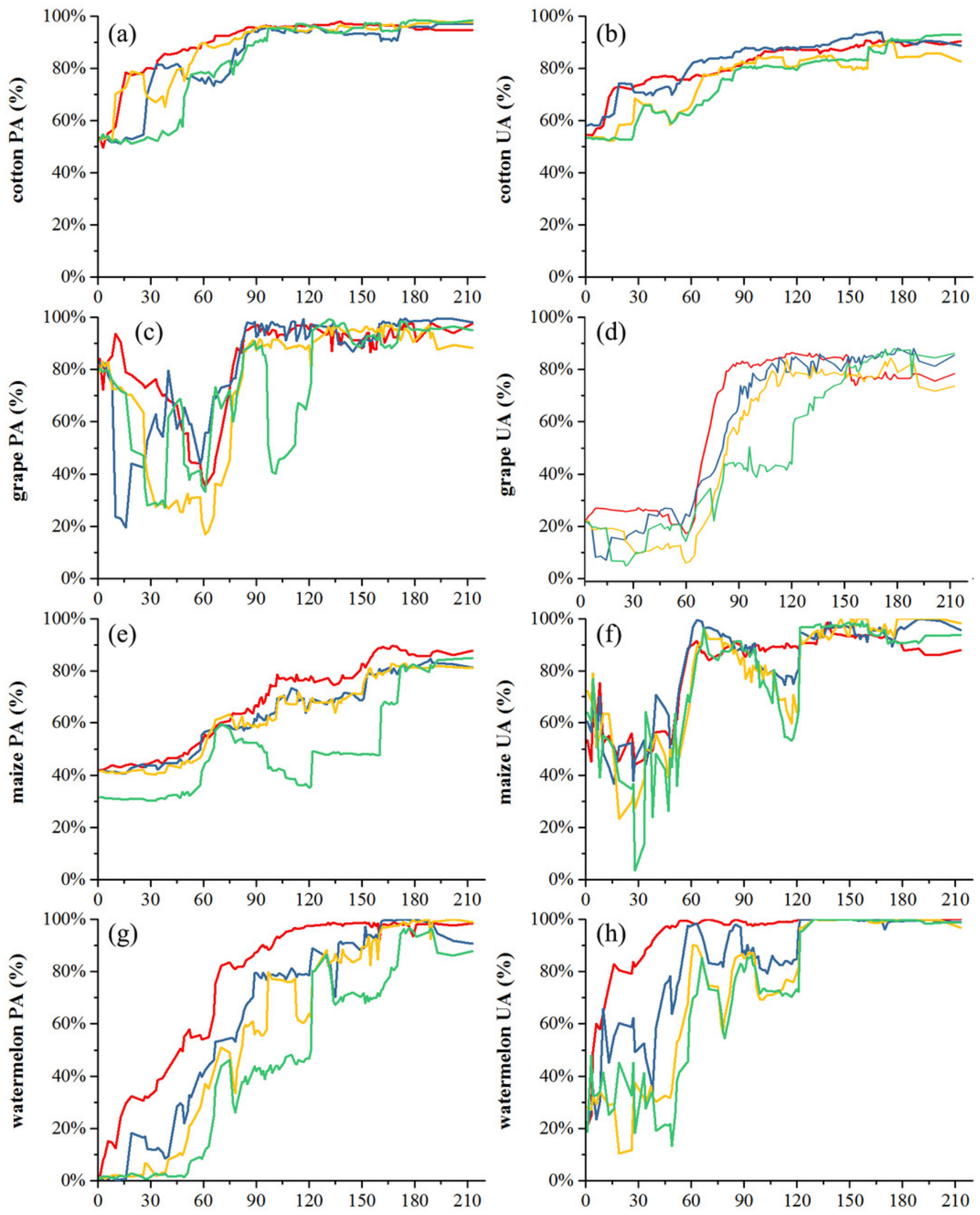

Time series Length

Time series Length

Daily -8 day -16 day -32 day 
Figure 10

Producer's accuracies and user's accuracies in Luntai 

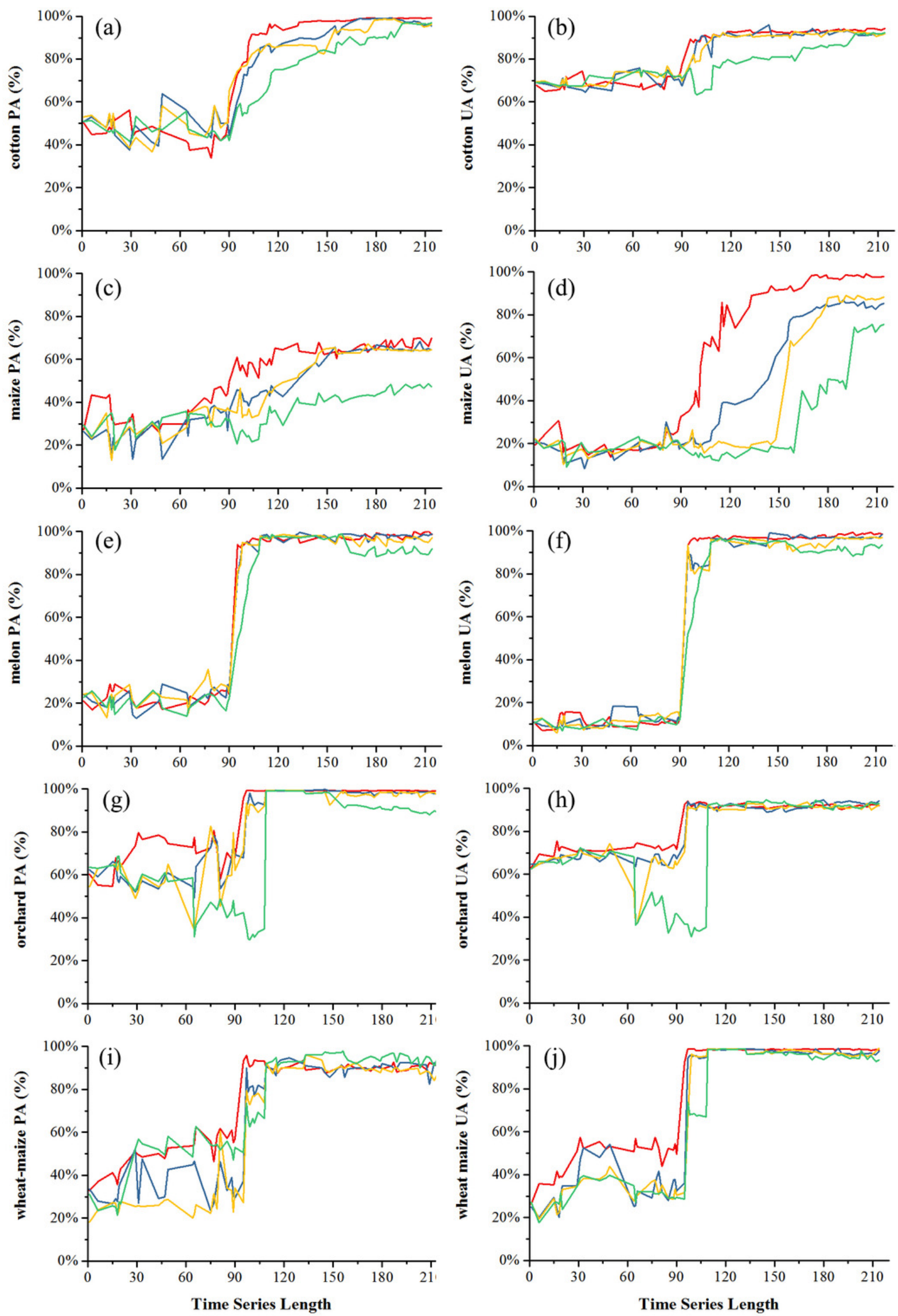
Figure 11

Temporal NDVI time series of some confusion crops

Black lines are the mean NDVI time series of each crop, blue line $s$ are the Standard Deviation as $\mathrm{Y}$ error
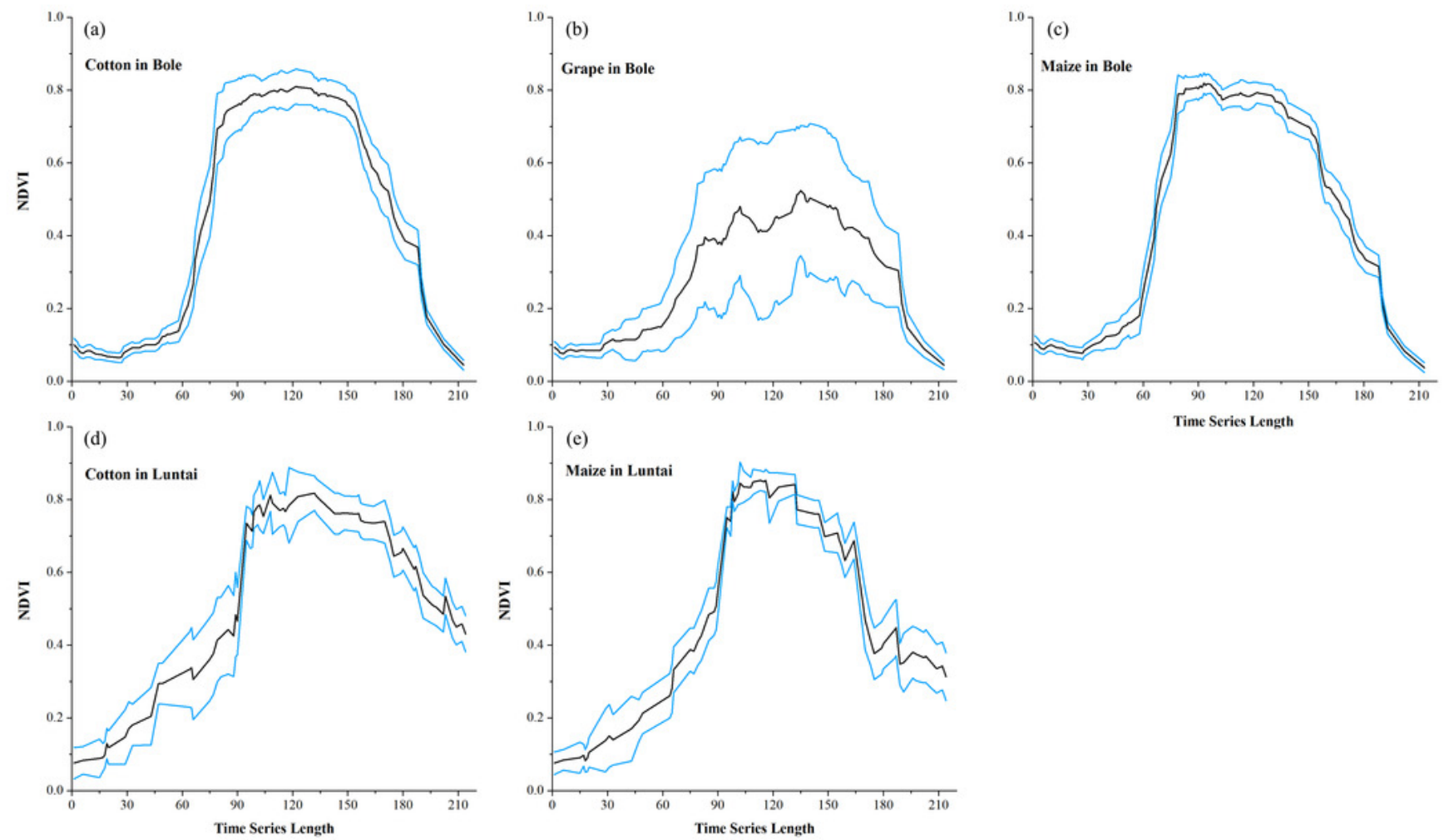
Figure 12

Classification uncertainty ratio in Bole and Luntai

(a)

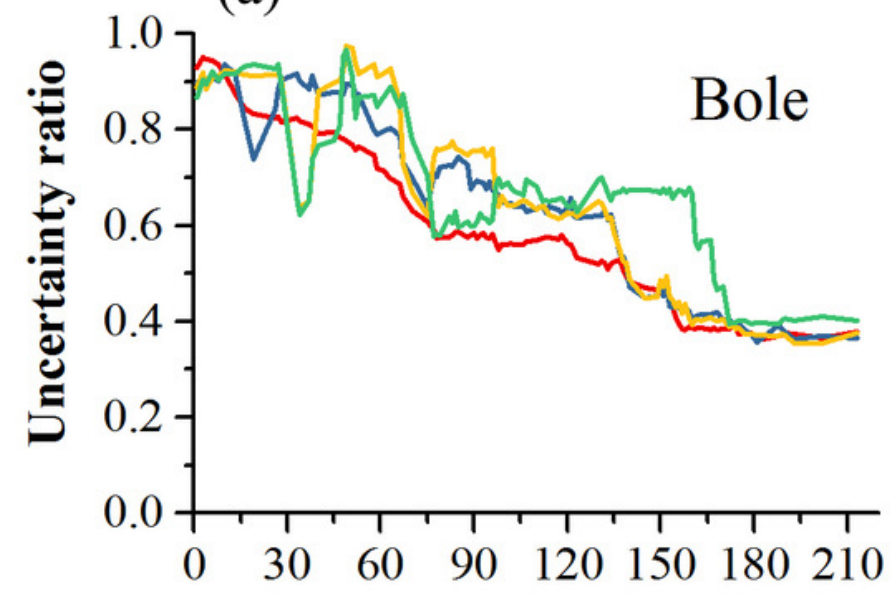

Time series Length (b)

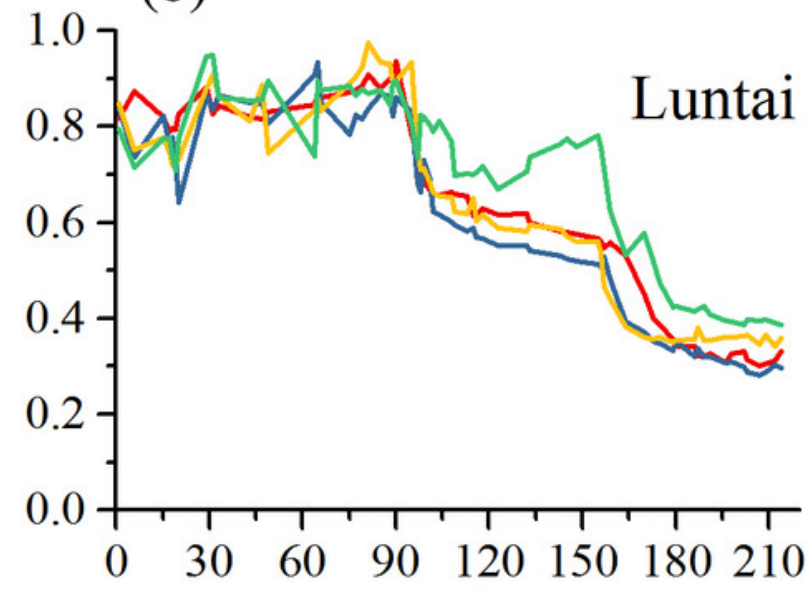

Time Series Length
Daily
8 day
16 day
32 day 


\section{Figure 13}

Subset Crop - type mapping in Bole

This Figure was obtained using images of the entire time series of each image composition strategies

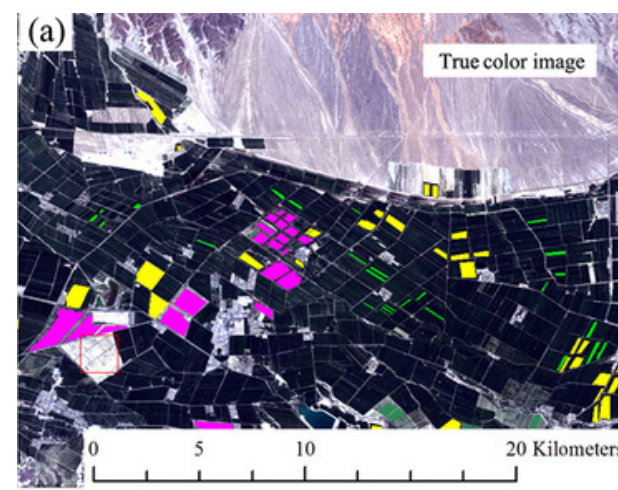

(b)

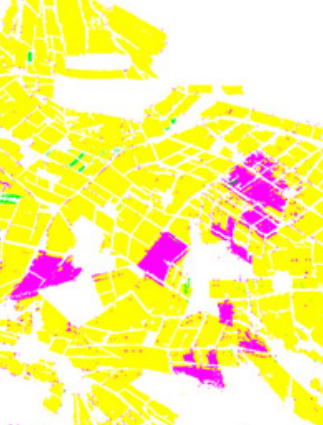

(d)

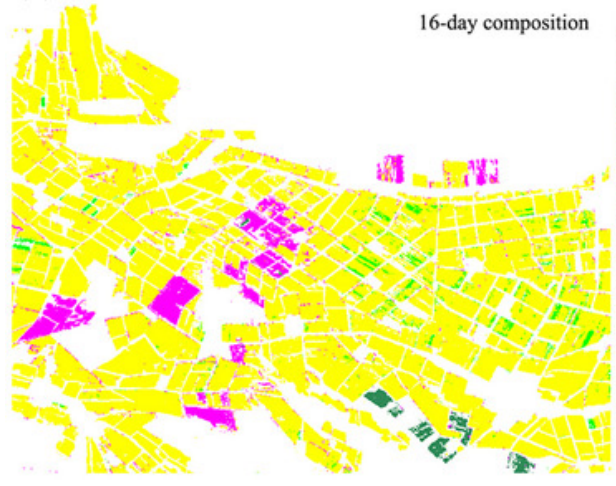

(e)
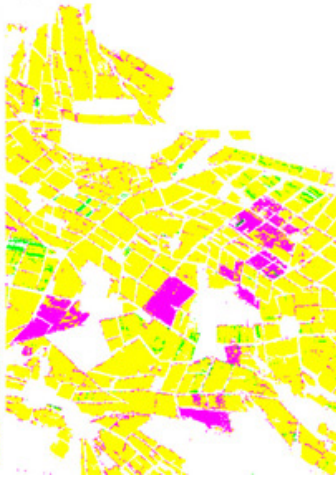

I H W

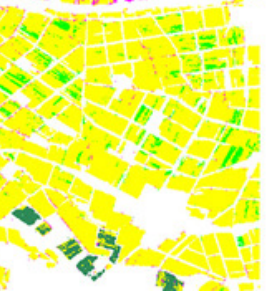

32-day composition (c)

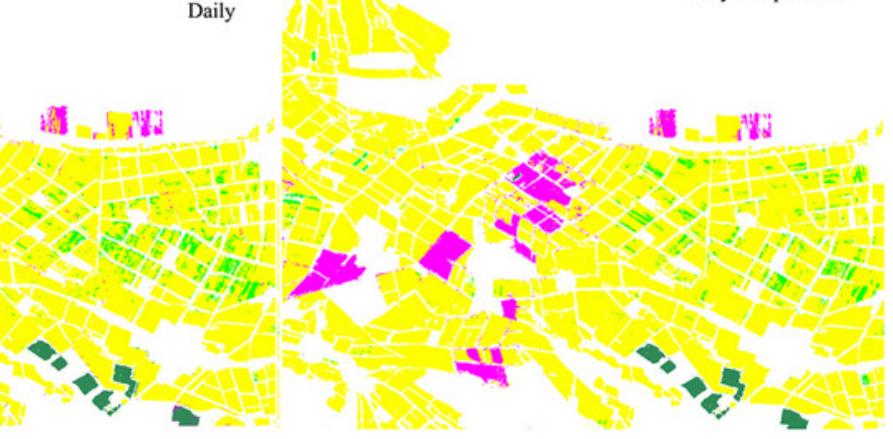

Cotton

Grape

Maize

Watermelon 


\section{Figure 14}

Subset Crop type mapping in Luntai

This Figure was obtained using images of the entire time series from each image composition strategy
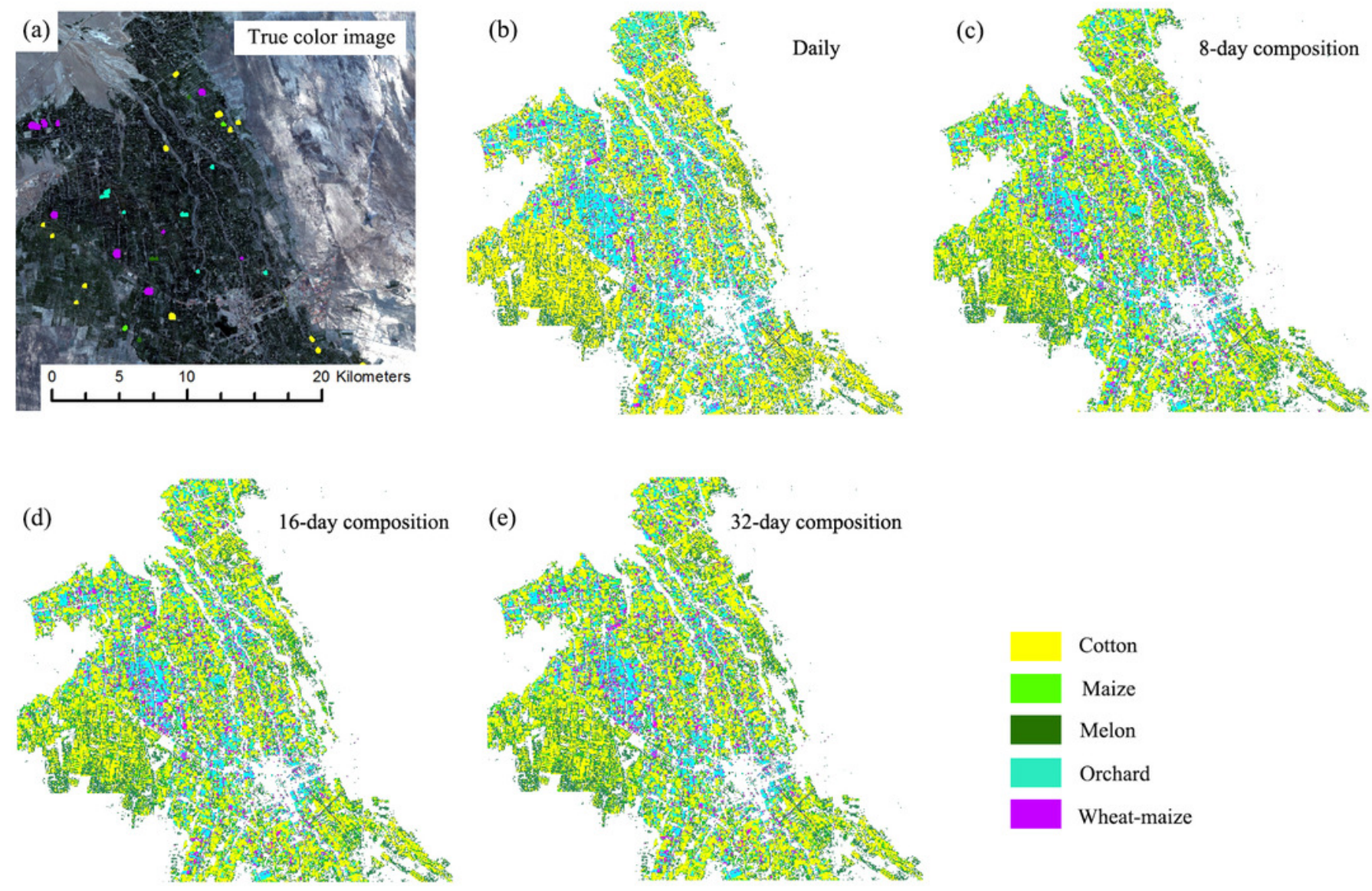


\section{Table $\mathbf{1}$ (on next page)}

Four image composition strategies 


\begin{tabular}{|c|c|c|c|c|}
\hline Data & Daily Composition & 8-day Composition & 16-day Composition & 32-day Composition \\
\hline 97 & $\mathrm{NDVI}_{97}$ & $\max \left(\mathrm{NDVI}_{97}\right)$ & $\max \left(\mathrm{NDVI}_{97}\right)$ & $\max \left(\mathrm{NDVI}_{97}\right)$ \\
\hline 98 & $\mathrm{NDVI}_{97}, \mathrm{NDVI}_{98}$ & $\max \left(\mathrm{NDVI}_{97} \sim \mathrm{NDVI}_{98}\right)$ & $\max \left(\mathrm{NDVI}_{97} \sim \mathrm{NDVI}_{98}\right)$ & $\max \left(\mathrm{NDVI}_{97} \sim \mathrm{NDVI}_{98}\right)$ \\
\hline 99 & $\begin{array}{l}\mathrm{NDVI}_{97}, \mathrm{NDVI}_{98}, \\
\mathrm{NDVI}_{99}\end{array}$ & $\max \left(\mathrm{NDVI}_{97} \sim \mathrm{NDVI}_{99}\right)$ & $\max \left(\mathrm{NDVI}_{97} \sim \mathrm{NDVI}_{99}\right)$ & $\max \left(\mathrm{NDVI}_{97} \sim \mathrm{NDVI}_{99}\right)$ \\
\hline 100 & $\begin{array}{l}\mathrm{NDVI}_{97}, \mathrm{NDVI}_{98}, \cdots \\
\mathrm{NDVI}_{100}\end{array}$ & $\max \left(\mathrm{NDVI}_{97} \sim \mathrm{NDVI}_{100}\right)$ & $\max \left(\mathrm{NDVI}_{97} \sim \mathrm{NDVI}_{100}\right)$ & $\max \left(\mathrm{NDVI}_{97} \sim \mathrm{NDVI}_{100}\right)$ \\
\hline 101 & $\begin{array}{l}\mathrm{NDVI}_{97}, \mathrm{NDVI}_{98} \cdots \\
\mathrm{NDVI}_{101}\end{array}$ & $\max \left(\mathrm{NDVI}_{97} \sim \mathrm{NDVI}_{101}\right)$ & $\max \left(\mathrm{NDVI}_{97} \sim \mathrm{NDVI}_{101}\right)$ & $\max \left(\mathrm{NDVI}_{97} \sim \mathrm{NDVI}_{101}\right)$ \\
\hline 102 & $\begin{array}{l}\mathrm{NDVI}_{97}, \mathrm{NDVI}_{98} \cdots \\
\mathrm{NDVI}_{102}\end{array}$ & $\max \left(\mathrm{NDVI}_{97} \sim \mathrm{NDVI}_{102}\right)$ & $\max \left(\mathrm{NDVI}_{97} \sim \mathrm{NDVI}_{102}\right)$ & $\max \left(\mathrm{NDVI}_{97} \sim \mathrm{NDVI}_{102}\right)$ \\
\hline 103 & $\begin{array}{l}\mathrm{NDVI}_{97}, \mathrm{NDVI}_{98} \cdots \\
\mathrm{NDVI}_{103}\end{array}$ & $\max \left(\mathrm{NDVI}_{97} \sim \mathrm{NDVI}_{103}\right)$ & $\max \left(\mathrm{NDVI}_{97} \sim \mathrm{NDVI}_{103}\right)$ & $\max \left(\mathrm{NDVI}_{97} \sim \mathrm{NDVI}_{103}\right)$ \\
\hline 104 & $\begin{array}{l}\mathrm{NDVI}_{97}, \mathrm{NDVI}_{98} \cdots \\
\mathrm{NDVI}_{104}\end{array}$ & $\max \left(\mathrm{NDVI}_{97} \sim \mathrm{NDVI}_{104}\right)$ & $\max \left(\mathrm{NDVI}_{97} \sim \mathrm{NDVI}_{104}\right)$ & $\max \left(\mathrm{NDVI}_{97} \sim \mathrm{NDVI}_{104}\right)$ \\
\hline 105 & $\begin{array}{l}\mathrm{NDVI}_{97}, \mathrm{NDVI}_{98} \cdots \\
\mathrm{NDVI}_{105}\end{array}$ & $\begin{array}{l}\max \left(\mathrm{NDVI}_{97} \sim \mathrm{NDVI}_{104}\right) \\
\max \left(\mathrm{NDVI}_{105}\right)\end{array}$ & $\max \left(\mathrm{NDVI}_{97} \sim \mathrm{NDVI}_{105}\right)$ & $\max \left(\mathrm{NDVI}_{97} \sim \mathrm{NDVI}_{105}\right)$ \\
\hline 106 & $\begin{array}{l}\mathrm{NDVI}_{97}, \mathrm{NDVI}_{98} \cdots \\
\mathrm{NDVI}_{106}\end{array}$ & $\begin{array}{l}\max \left(\mathrm{NDVI}_{97} \sim \mathrm{NDVI}_{104}\right) \\
\max \left(\mathrm{NDVI}_{105}, \mathrm{NDVI}_{106}\right)\end{array}$ & $\max \left(\mathrm{NDVI}_{97} \sim \mathrm{NDVI}_{106}\right)$ & $\max \left(\mathrm{NDVI}_{97} \sim \mathrm{NDVI}_{106}\right)$ \\
\hline 107 & $\begin{array}{l}\mathrm{NDVI}_{97}, \mathrm{NDVI}_{98} \cdots \\
\mathrm{NDVI}_{107}\end{array}$ & $\begin{array}{l}\max \left(\mathrm{NDVI}_{97} \sim \mathrm{NDVI}_{104}\right) \\
\max \left(\mathrm{NDVI}_{105}, \mathrm{NDVI}_{107}\right)\end{array}$ & $\max \left(\mathrm{NDVI}_{97} \sim \mathrm{NDVI}_{107}\right)$ & $\max \left(\mathrm{NDVI}_{97} \sim \mathrm{NDVI}_{107}\right)$ \\
\hline 108 & $\begin{array}{l}\mathrm{NDVI}_{97}, \mathrm{NDVI}_{98} \cdots \\
\mathrm{NDVI}_{108}\end{array}$ & $\begin{array}{l}\max \left(\mathrm{NDVI}_{97} \sim \mathrm{NDVI}_{104}\right) \\
\max \left(\mathrm{NDVI}_{105}, \mathrm{NDVI}_{108}\right)\end{array}$ & $\max \left(\mathrm{NDVI}_{97} \sim \mathrm{NDVI}_{108}\right)$ & $\max \left(\mathrm{NDVI}_{97} \sim \mathrm{NDVI}_{108}\right)$ \\
\hline 109 & $\begin{array}{l}\mathrm{NDVI}_{97}, \mathrm{NDVI}_{98} \cdots \\
\mathrm{NDVI}_{109}\end{array}$ & $\begin{array}{l}\max \left(\mathrm{NDVI}_{97} \sim \mathrm{NDVI}_{104}\right) \\
\max \left(\mathrm{NDVI}_{105}, \mathrm{NDVI}_{109}\right)\end{array}$ & $\max \left(\mathrm{NDVI}_{97} \sim \mathrm{NDVI}_{109}\right)$ & $\max \left(\mathrm{NDVI}_{97} \sim \mathrm{NDVI}_{109}\right)$ \\
\hline 110 & $\begin{array}{l}\mathrm{NDVI}_{97}, \mathrm{NDVI}_{98} \cdots \\
\mathrm{NDVI}_{110}\end{array}$ & $\begin{array}{l}\max \left(\mathrm{NDVI}_{97} \sim \mathrm{NDVI}_{104}\right) \\
\max \left(\mathrm{NDVI}_{105}, \mathrm{NDVI}_{110}\right)\end{array}$ & $\max \left(\mathrm{NDVI}_{97} \sim \mathrm{NDVI}_{110}\right)$ & $\max \left(\mathrm{NDVI}_{97} \sim \mathrm{NDVI}_{110}\right)$ \\
\hline 111 & $\begin{array}{l}\mathrm{NDVI}_{97}, \mathrm{NDVI}_{98}, \cdots \\
\mathrm{NDVI}_{111}\end{array}$ & $\begin{array}{l}\max \left(\mathrm{NDVI}_{97} \sim \mathrm{NDVI}_{104}\right) \\
\max \left(\mathrm{NDVI}_{105}, \mathrm{NDVI}_{111}\right)\end{array}$ & $\max \left(\mathrm{NDVI}_{97} \sim \mathrm{NDVI}_{111}\right)$ & $\max \left(\mathrm{NDVI}_{97} \sim \mathrm{NDVI}_{111}\right)$ \\
\hline 112 & $\begin{array}{l}\mathrm{NDVI}_{97}, \\
\mathrm{NDVI}_{98}, \cdots \mathrm{NDVI}_{112}\end{array}$ & $\begin{array}{l}\max \left(\mathrm{NDVI}_{97} \sim \mathrm{NDVI}_{104}\right) \\
\max \left(\mathrm{NDVI}_{105}, \mathrm{NDVI}_{112}\right)\end{array}$ & $\max \left(\mathrm{NDVI}_{97} \sim \mathrm{NDVI}_{112}\right)$ & $\max \left(\mathrm{NDVI}_{97} \sim \mathrm{NDVI}_{112}\right)$ \\
\hline 113 & $\begin{array}{l}\mathrm{NDVI}_{97}, \mathrm{NDVI}_{98}, \cdots \\
\mathrm{NDVI}_{113}\end{array}$ & $\begin{array}{l}\max \left(\mathrm{NDVI}_{97} \sim \mathrm{NDVI}_{104}\right), \\
\max \left(\mathrm{NDVI}_{105}, \mathrm{NDVI}_{112}\right), \\
\max \left(\mathrm{NDVI}_{113}\right)\end{array}$ & $\begin{array}{l}\max \left(\mathrm{NDVI}_{97} \sim \mathrm{NDVI}_{112}\right), \\
\max \left(\mathrm{NDVI}_{113}\right)\end{array}$ & $\max \left(\mathrm{NDVI}_{97} \sim \mathrm{NDVI}_{113}\right)$ \\
\hline
\end{tabular}




\section{Table 2 (on next page)}

Number of surveyed fields, training and validation samples in the study area 


\begin{tabular}{ccccc}
\hline & \multicolumn{2}{c}{ Training } & \multicolumn{2}{c}{ Validation } \\
\cline { 2 - 5 } & Polygon Number & Sample number & Polygon Number & Sample number \\
\hline Bole & 54 & 1510 & 29 & 486 \\
Cotton & 26 & 852 & 11 & 130 \\
Grape & 28 & 657 & 23 & 210 \\
Maize & 7 & 726 & 5 & 232 \\
Watermelon & & & & \\
\hline Luntai & 50 & 309 & 44 & 236 \\
Cotton & 20 & 138 & 18 & 89 \\
Maize & 19 & 106 & 12 & 91 \\
Melon & 23 & 118 & 25 & 74 \\
Orchard & 22 & 111 & 29 & \\
Wheat-Maize & & & & \\
\hline
\end{tabular}

1 


\section{Table 3(on next page)}

Shortest time series length when both the PA and UA were higher than $85 \%$

"-" in the table either PA or UA of the crop was lower than $85 \%$ using the corresponding composition strategy 


\begin{tabular}{lrrrrr}
\hline Bole & \multicolumn{1}{c}{ Cotton } & \multicolumn{1}{c}{ Grape } & Maize & Watermelon & \\
\hline Daily & 85 & 90 & 156 & 89 & \\
8-day & 102 & 112 & 190 & 123 & \\
16-day & 107 & 121 & 202 & 131 & \\
32-day & 162 & 153 & & 131 & 97 \\
\hline Luntai & & & & & \\
& Cotton & Maize & Melon & Orchard & Wheat-maize \\
\hline Daily & 104 & - & 97 & 97 & 113 \\
8-day & 113 & - & 113 & 98 & 113 \\
16-day & 115 & - & 113 & 98 & 113 \\
32-day & 170 & - & 109 & 115 & \\
\hline
\end{tabular}

1 